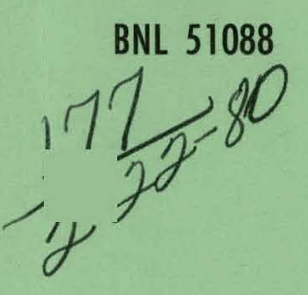

\title{
REPORT ON THE \\ COMBUSTION RESEARCH CONTRACTORS' MEETING
}

\author{
SPONSORED BY \\ U.S. DEPARTMENT OF ENERGY \\ OFFICE OF BASIC ENERGY SCIENCES \\ DIVISION OF CHEMICAL SCIENCES
}

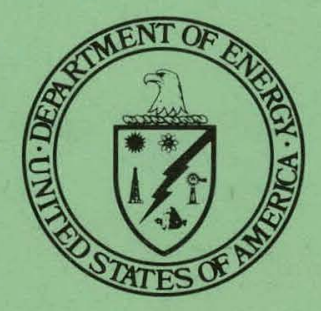

October 9-11, 1979

HELD AT

BROOKHAVEN NATIONAL LABORATORY

UPTON, NEW YORK

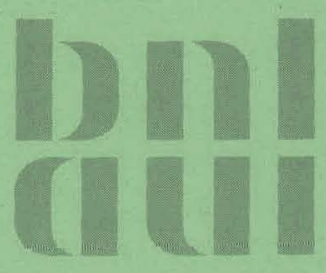




\section{DISCLAIMER}

This report was prepared as an account of work sponsored by an agency of the United States Government. Neither the United States Government nor any agency Thereof, nor any of their employees, makes any warranty, express or implied, or assumes any legal liability or responsibility for the accuracy, completeness, or usefulness of any information, apparatus, product, or process disclosed, or represents that its use would not infringe privately owned rights. Reference herein to any specific commercial product, process, or service by trade name, trademark, manufacturer, or otherwise does not necessarily constitute or imply its endorsement, recommendation, or favoring by the United States Government or any agency thereof. The views and opinions of authors expressed herein do not necessarily state or reflect those of the United States Government or any agency thereof. 


\section{DISCLAIMER}

Portions of this document may be illegible in electronic image products. Images are produced from the best available original document. 


\title{
REPORT ON THE \\ COMBUSTION RESEARCH CONTRACTORS' MEETING
}

\author{
SPONSORED BY \\ U.S. DEPARTMENT OF ENERGY \\ OFFICE OF BASIC ENERGY SCIENCES \\ DIVISION OF CHEMICAL SCIENCES
}

HELD AT

BROOKHAVEN NATIONAL LABORATORY

UPTON, NEW YORK 11973

OCTOBER 9-11, 1979

Edited by

R.B. Klemm and J.T. Muckerman

BROOKHAVEN NATIONAL LABORATORY

ASSOCIATED UNIVERSITIES, INC.

UNDER CONTRACT NO: DE-AC02.76CH00016 WITH THE

UNITED STATES DEPARTMENT OF ENERGY

This book was prepared as an account of work sponsored by an agency of the Unized States Government. Neither the United States Government nor any ogency thereof, nor any of their employees, makes any

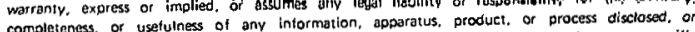
completeness, or usefulness of anv intormation, apparatus, product. or process absom, specific

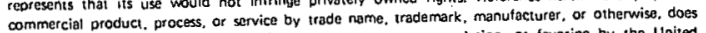




\section{DISCLAIMER}

This book was prepared as an account of work sponsored by an agency of the United States Government. Neither the United States Government nor any agency thereof, nor any of their employees, makes any warranty, express or implied, or assumes any legal liability or responsibility for the accuracy. completeness, or usefulness of any information, apparatus, product, or process disclosed, or represents that its use would not intringe privately owned rights. Reference herein to any epecific commercial product, process, or service by trade name, trademark, manufacturer, or otherwise, does not necessarily constitute or imply its endorsement, recommendation, or favoring by the United States Government or any agency thereof. The views and opinions of authors expressed herein do not necessarily state or reflect those of the United States Government or any agency thereof.

Printed in the United States of America Available from

National Technical Information Service

U.S. Department of Commerce

5285 Port Royal Road

Springfield, VA 22161

Price: Printed Copy $\$ 25$; Microfiche $\$ 3.00$

$$
7.0
$$


REPORT ON

DOE BASIC ENERGY SCIENCES

COMBUSTION RESEARCH CONTRACTORS' MEETING

October 9-11, 1979
Upton, New York

TABLE OF CONTENTS

Page No.

SESSION I - Genera1 and NSLS Status

Chairman - R. B. Klemm

Introduction - 0. W. Adams . . . . . . . . . . . . $1-5$

National Synchrotron Light Source - M. R. Howelis . . . . . . . . 6 "

Energy Transfer Studies at the Brookhaven National Synchrotron

Light Source - R. E. Weston .................. . 7

Research with Molecular Beams at the Brookhaven National

Synchrotron Light Source - J. R. Grover and J. B. A. Mitchell . . . . 8

Flame Probe Studies on the NSLS - R. B. Klemm ... . . . . . . . . . 9-10

$$
\begin{gathered}
\text { SESSION II - Theory of Reactivity and Chemical } \\
\text { Dynamics in Combustion } \\
\text {. Chairman - J. T. Muckerman }
\end{gathered}
$$

NRCC Developments and Theoreticians Ad Hoc Group - W. A. Leșter . . . 11

Study of Unimolecular Dissociation Reactions and Recombination

Reactions - N. J. Brown .................... 12

Theoretical FORS Calculations of Combustion Reactions - K. Ruedenberg • 13

Chemical Species and Reaction Involved in Combustion - T. H. Dunning, Jr.

S. P. Walch, A. F. Wagner, G. C. Schatz, and J. M. Bowman . . . . . . 14-15

Properties of Intermediate Complexes in Reactive Collisions of

$O\left({ }_{D}{ }^{D}\right)$ with $H_{2}$, $\mathrm{HD}$, and $D_{2}$ - J. T. Muckerman . . . . . . . . $16^{\prime}$

Interactions between Hydrocarbons and Transition Metal

Clusters - M. D. Newton ................... 17

Theoretical Studies in Heterogeneous Combustion - C. K. Law . . . . . . 18

Sensitivity Analysis in Chemical Kinetics and Quantum Dynamics -

H. Rabitz . . . . . . . . . . . . . . . . . . . 19-20

Theoreticians - Informal Session - W. A. Lester, Jr. . . . . . . . 21-22 
Page No.

SESSION III - Kinetics of Combustion Reactions-I
Chairman - J. R. Grover

Combustion Kinetics Data Evaluation - w. Tsang . . . . . . . . . .

High-Temperature Photochemistry (HI'P) Studies of Isolated

Elementary Combustion Reactions - A. Fontijn and Felder . . . . . . . . . 24

Combustion Studies of Alternative Fuels - R. B: Klemm . . . . . . . . 25

A Kinetic Study of Radical-Aromatic Hydrocarbon Reacliuns -

F. P. Tully and A. R. Ravishankara . . . . . . . . . . . . . . 26

Studies of Combustion Kinetics and Mechanisms - D. Gutman . . . . . . . . 27

Pyrolytic and Reaction Intermediates by ESR - R. LlvLuystuil dind

H. Zeldes . . . . . . . . . . . . . . . . . . . 28

Flash Photolysis Studies: Reactions of $\mathrm{CH}_{3}$, $\mathrm{HCO}$, and $\mathrm{HO}_{2}-$

C. J. Hochanadel and T. J. Sworski .................. 29

High Resolution Photoionization Studies of Some Simple Molecules

near the Thresholds - C. Y. Ng . . . . . . . . . . . . . 30-31

The Crossed Beam Studies on Reactions of $O\left({ }^{3} P\right)$ and $O\left({ }^{1} D\right)-$

R. J. Buss and Y. T. Lee . . . . . . . . . . . . . . . 32

Low Energy Ion-Molecule Reactions and Chemilonization Kinetics -

J. M. Farrar . . . . . . . . . . . . . . . . . . . 33

Infrared Laser Induced Photochemistry - W. A. Guillory . . . . . . . 34

Energy Transfer Studies Using Highly Vibrationally Excited Azulene -

J. R. Barker, T. Rothem, and P. L. Trevor . . . . . . . . . . 35

$$
\begin{gathered}
\text { SESSION IV - Kinetics of Combustion Kéáctons-II } \\
\text { Chairman - R. E. Weston }
\end{gathered}
$$

Flame Research - M. A. Gusinow .. . . . . . . . . . . . 36

Programs at the Combustion Research Facility - D. L. Hartley . . . . . 37

Kinetics of Some Reactions of HCN at High Temperatures -

R. K. Hanson, C. T. Bowman, and A. Szekely . . . . . . . . . 38

Obtaining Positive Evidence for the Importance of Various Processes in

Soot Formation in Flames - R. G. Gann, W. G. Mallard, and K. C. Smyth . . . 39

Experimental Study of Combustion in a Turbulent Boundary Layer -

F. Robben, R. K. Chen, R. G. Bill, Jr., and L. Talbot . . . . . ... 40 
Page No.

Turbulent Reacting Flow Studies - D. R. Hardesty . . . . . . . . . . . 41

Combustion of Nitrogen and Sulfur Bearing Fuels - K. Schofield and

M. Steinberg . . . . . . . . . . . . . . . . . 42

Laser Schlieren/Shock. Tube Studies of Hydrocarbon Phrolysis -

J. H. Kiefer . . . . . . . . . . . . . . . . . 4 43

The Direct Determination of Atom and Radical Concentrations in

Thermal Reactions of Hydrocarbons and other Gases - G. B. Skinner . . . . 44

High Temperature Fast Flow Reactor Studies of Fuel Nitrogen Reactions -

W. J. McLean . . . . . . . . . . . . . . . . . . 4 45

Pulse Radiolysis Studies on Reactions Related to Combustion and

Air Pollution - S. Gordon, M. C. Sauer, C. Jonah, and R. Lii . . . . . . . 46-47

CHEMKIN: A Generalized Chemical Kinetics Code Package - R. J. Kee . $\because$ - 48

The Dissociative Recombination of $\mathrm{H}_{3} \mathrm{O}^{+}$- J. B. A. Mitche11, P. M. Mul,

and J. Wm. McGowan . . . . . . . . . . . . . . . . . . . 49

Kineticists - Informa1 Session - D. Gutman . . . . . . . . . . . . 50-51

SESSION V - Laser Diagnostics for High Temperature

and Combustion Systems

Chairman - A. J. Campillo

Combustion Gas Measurements Using Tunable Laser Absorption

Spectroscopy - R. K. Hanson . . . . . . . . . . . . . . . . 52

Measurement of Radical Species Concentrations in Flames by Fluorescence.

and Absorption Using a Tunable Dye Laser - N. M. Laurendeau, D. W. Sweeney,

and R. P. Lucht . . . . . . . . . . . . . . . . . . . b3

Line Shape Studies in Intracavity Absorption - G. O. Brink . . . . . . . 54 .

Real Time Optical Diagnostics - R. Goulard . . . . . . . . . . . . 55

Advanced Diagnostic Methods for Combustion Research - P. 0. Mattern . . 56

Spectroscopy of Some Combustion Related Species . . . . . . . . . . 57

LIST OF PARTICIPANTS ........ . 58-61 
Acknowledgment

The sponsor and organizers of this meeting would like to-express their appreclation to the people at $\bar{B}$ in who contributed substan-; tially to the neeeds and comfort of the participants:

Dorothy Pollock and Elaine Rowland - meeting secretaries;

Virginia Sayre and Dorothy Schroeder - housing and travel

arrangements; Patrick Glynn - meeting room and refreshment arrangements; and Henry Boyd - dinner arrangements. 


\title{
INTRODUCTION
}

\author{
0. W. Adams \\ Fundamental Interactions Branch \\ Division of Chemical Sciences \\ Office of Basic Energy. Sciences, DOE
}

This report covers the second annual. chemical physics combustion contractor review meeting held at Brookhaven National Laboratory on October 9-10, 1979. It includes abstracts of the presentations given by all the individuals currently supported by the Chemical Physics Program, Office of Basic Energy Sciences (BES)/DOE, except those whose contracts were initiated in FY 1979.

The objective of the meeting is to allow us at DOE to view the entire basic combustion program at one time as well as to bring together. a rather diverse group of scientists and engineers to discuss problems of mutual interest from their own particular point of view. The first. objective not only gives us a mechanism for reviewing the progress on the individual projects but also to detect gaps in our support. In this connection I should restate, as a point of reference, that the four major components of the BES chemical physics combustion program are chemical kinetics, chemical theory, spectroscopy and combustion diagnostics.

In retrospect, I found the meeting very interesting and informative. The many comments I have received from other participants lead me to believe that my assessment is not unique by any means. There are indeed gaps in the program, but we are moving to fill these as the BES combustion program grows.

Let me summarize here some of the budget data that I presented at the beginning of the meeting, just to point up the fact that the combustion program is growing and to give you some idea of the size of that effort within the overal1 BES budget.

Table I shows the budget of BES for FY 1979 and FY 1980 in terms of operating expenses (i.e. it does not include funds for equipment and construction at the various national laboratories). The FY 1979 figures are actual expenditures; those for FY 1980 are planned expenditures. The numbers that contain the chemical physics combustion program are those for the Division of Chemical Sciences, for which there is an increase of $14.8 \%$ between the two years. A smaller component of the BES combustion program is contained in the Division of Engincoring, Mathematics and Geo-Sciences (see Table III). 
A more detailed breakdown of the FY 1979-1980 budget for the Division of Chemical Sciences is shown in Table II. In this table the Chemical Physics program is shown explicitly. It shows a healthy growth of more than 2 million dollars in FY 1980 over the previous. year. This growth will allow us to begin some new contracts in FY. 1980 as well as giving modest increases to ongoing contracts, which we had to hold essentially constant between FY 1978 and 1979. Both new contracts and increases in renewed contracts will, however, be limited by the need to meet prior year commitments, one example being the expanding combustion effort at the Sandia Livermore Laboratory.

Table III shows the dollar levels for the total BES combustion research program in the three recent fiscal years. While the largest single romponent. is in the Chemical Physics program, the other programs add a healthy amount to the total figure. The last two rows in the table are the combustion projects mentioned earlier as being contained in the Division of Engineering, Mathematics and Geo-Sciences.

While no attempt has been made to include FY 1980 figures in Table III, it is estimated that the total figure for the BES combustion effort will be very close to 6 million dollars by the end of the year. 


\section{TABLE I}

BASIC ENERGY SCIENCES

Operating EXPEnses, FY 1979 and FY 1980

(\$ IN THOUSANDS)

\begin{tabular}{|c|c|c|}
\hline Division & FY 1979 & FY 1980 \\
\hline NUUCLEAR SCIENCES & 28,400 & 30,700 \\
\hline Materials Sciences & 71,520 & 79,000 \\
\hline Chemical SCiences & 48,000 & 55,100 \\
\hline $\begin{array}{l}\text { Engineering, Math } \\
\& \text { Geo-Sciences }\end{array}$ & 15,700 & 20,100 \\
\hline AdVAnced Energy Projects & 7,300 & 10,000 \\
\hline Biological EnERgy Research & $4 ; 000$ & 6,000 \\
\hline
\end{tabular}


TABLE II

CHEMICAL SCIENCES

OPERATing EXPENSES, FY 1979 and FY 1980

( $\$$ IN THOUSANDS)

\section{PROGRAM}

Chemical Energy

SEPARATIONS.

ANALYSIS

Chemical Engineering Sciences
FY 1979

(ACTUAL)

9,800

5,362

3,658

624
FY 1980

(PLANNED)

11,410

5,935

4,115

1,135

Processes and TeChniques Total 19,444

\begin{tabular}{lrr} 
Radiation SCIEnCES & 12,172 & 14,327 \\
Chemical Physics & 10,859 & 13,003 \\
Atomic Physics & 4,662 & 5,175 \\
\hline \multicolumn{1}{c}{ Fundamental Interactions Total } & 27,693 & 32,505 \\
\multicolumn{1}{c}{ Chemical SCIENCES TOTAL } & 47,137 & 55,100 \\
& $(48,000)$ &
\end{tabular}


TABLE III

Funding of Combustion Research

BASIC ENERGy SCIENCES

( $\$$ IN THOUSANDS)

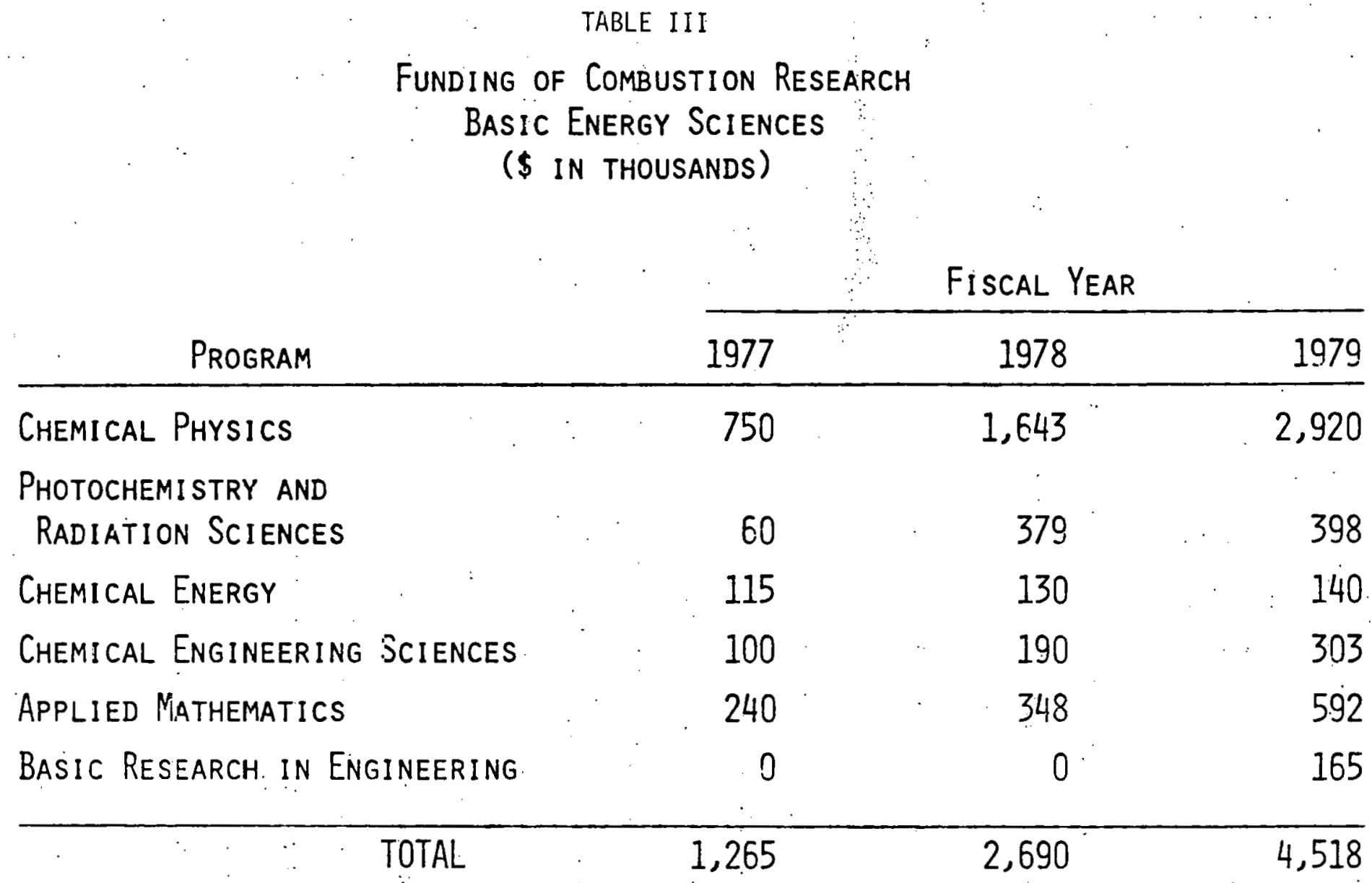


NATIONAL SYNCHROTRON LIGHT SOURCE

\author{
Malcolm R. Howells \\ Accelerator Department \\ Brookhaven National Laboratory \\ Upton, NY 11973
}

The specifications for the windowlces gae phase beam line call for as high a photon flurt ao poooiblo with moderate wavelength resolution ( $20.25 \AA$ ) over a spectral range from 300-2000. Various monochromator designs have been examined to match these specifications as closely as possible, considerable emphasis being placed on limiting the expense of such a system. The most suitable design appears to be a normal incidence instrument collecting photons over an angular range of $75 \mathrm{mrad}$ in the horizontal plane and $10 \mathrm{mrad}$ in the vertical. The photon flux output for this instrument can be estimated using the design parameters for the $700 \mathrm{MeV}$ VUV storage ring of the NSLS. It should be possible with clean reflecting surtaces to obtain beams of $\sim 10^{13}$ photons $/ \mathrm{sec}$ at $\lambda=1000 \AA$ for a bandwidth of $\sim 0.25 \AA$. By changing to gratings with higher groove densities it is possible to improve on this resolution although the wavelength range is subsequently diminished. Correspondingly, coarser gratings give better wavelength range and worse resolution.

Specifications for the windowed gas phase beam line are based on different criteria, primarily a much different wavelength range. Further technical details concerning both the windowless and windowed beam line monochromators, and their coupling to the storage ring will be discussed. 
ENERGY TRANSFER STUDIES AT THE BROOKHAVEN NATIONAL SYNCHROTRON LIGHT SOURCE

\author{
Ra1ph E. Weston \\ Department of Chemistry \\ Brookhaven National Laboratory \\ . Upton, NY 11973
}

Under construction at Brookhaven National Laboratory are two electron storage rings to be dedicated exclusively to the production of photons. The smaller of these $(0.7 . \mathrm{GeV})$, which will provide radiation covering the spectral range from $\sim 10 \AA$ to the infrared, should be available for use in 1981. The temporal properties of this synchrotron radiation (Table I) make this facility very attractive for the study of lifetimes of electronically excited states of atoms and molecules, and the rates of energy transfer from such states. To this end, a beam line now being designed will include a small vacuum. monochromator of moderate resolution (1-2 $\AA$ ) with a spectral range down to i $1200 \AA$. Also to be included are a sample handling system for solutions, gases, and substances with low vapor pressures at ambient temperature; also, appropriate detectors and signal processing electronics.for single-photon time correlation experiments will be provided. A number of investigators have expressed interest in using this facility, and others are invited to express any interest they may have.

Table I

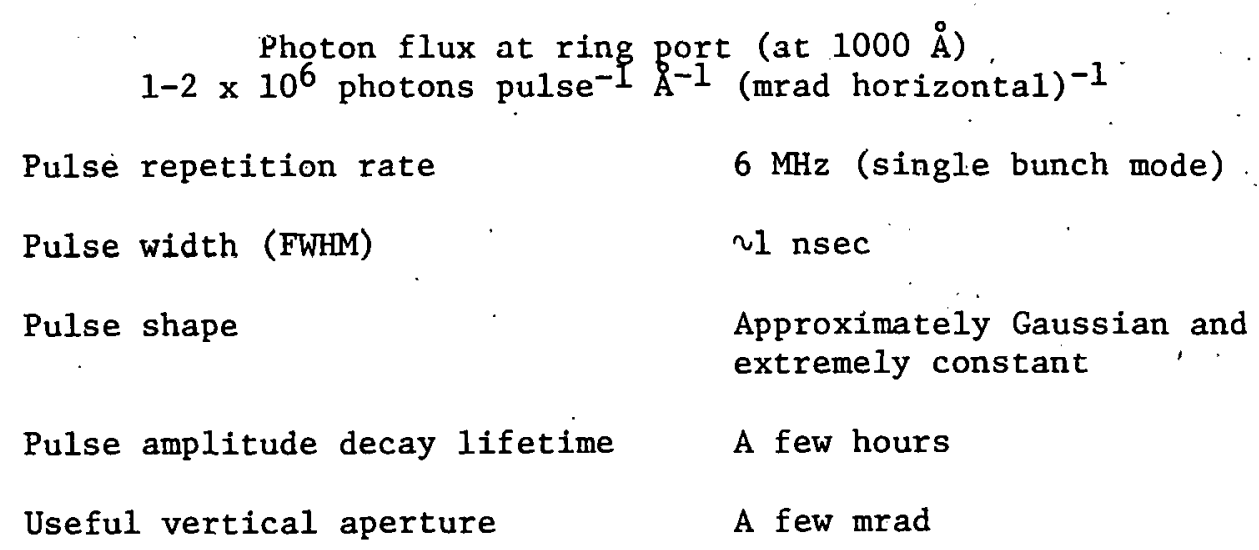


RESEARCH WITH MOLECULAR BEAMS AT THE

BROOKHAVEN NATIONAL SYNCHROTRON LIGHT SOURCE

J. R. Grover and J. B. A. Mitche11

Department of Chemistry

Brookhaven National Laboratory

Upton, NY 11973

We are considering two lines of investigation using the windowless gas phase beamline on the NSLS; both will exploit a nozzle beam apparatus. (1) Formation energetics and reactivities of clusters.

(2) VUV photoionization spectroscopy of cooled free rad1cals and small reactive molecules.

Investigations of clusters of carbon atoms and of hydrogen-poor hydrocarbons such as polyacetylenes will be undertaken to seek insight into soot formation. Studies of transition metal clusters will also be tried, from the viewpoint of understanding catalysis of fuel oxidation.

The work with free radicals and reactive molécules is d1recred to analyses, under single-collision conditions, of transient species arising from combustion reactions. The ultimate goals include disentanglement and identification of product species and the measurement of excitation energy distributions. Initially, however, molecular beams of the expected product species will be prepared using discharge flow tubes, diffusion flames, and other approxpriate techniques, and seeded into helium followed by a subsequent nozzle expansion to achieve strong cooling. The photoionization excitation functions of these cooled species will provide the requisite catalogue of reference spectra. Many specicä Importane to combuetion have nul petviuusly bieis suhjerted ton photoionization spectroscopy because of the difficulty of the measurements at low concentration, e.g. $\mathrm{CH}, \mathrm{CH}_{2}, \mathrm{CH}_{3}, \mathrm{C}_{2} \mathrm{H}$. However, the high intensity and tunability of the VUV beams from the NSLS should help greatly to alleviate this problem. 
FLAME PROBE STUDIES ON THE NSLS

\author{
R. Bruce Klemm \\ Department of Energy and Environment \\ Brookhaven National Laboratory \\ Upton, NY 11973
}

This experiment will utilize, and depend upon, the essential components of the apparatus described in the preceding presentation. As planned, this experiment will be operated by the DEE/Chem. Sci. Div. Alternative Fuels Combustion Project in collaboration with Drs. D. J. Seery and M. F. Zabielski of United Technologies Research Center and Drs. J. Peeters and C. Vinckier of the University of Leuven, Belgium. In addition, Drs. Seery and Zabielski are contemplating the use of the proposed apparatus for flame probe experiments of their own, with external support. Basically, this experiment is designed to identify radical and intermediate species that exist in flames using various fuels, oxidants, and diluent gases. The immediate purpose of the work is to gain information of reaction mechanisms and pathways. The burner used in this work will be of the cooled, porous plug, flat flame design. The transport properties of the gases in the flame in this. type of burner are reasonably well defined. The flame is also stable over a wide range of air-fuel ratio, and thus maximum flame temperature; and the radial profile of the flame is very uniform. A windowless beam line is required for this work to obtain sufficient energetic photons to ionize a majority of radicals and molecules of interest (see Table). The results of this experiment are expected to yield information on the mechanisms of oxidation and pollutant formation reactions, to identify the most important reactions (via sensitivity analysis) and to obtain estimates of bimolecular rate constants at high temperatures by computer fitting of the experimental species profiles using a flame model that includes reaction kinetics. 
Ionization Potentials of Some Important Flame Species ${ }^{a}$

\begin{tabular}{|c|c|c|c|c|c|}
\hline Species & I.P. & Species & I.P. & Species & I.P. \\
\hline $\mathbf{H}$ & $13.5^{*}$ & $\mathrm{HO}_{2}$ & $11.5^{* \star}$ & $\mathrm{HCN}$ & $13.8^{*}$ \\
\hline \multirow[t]{2}{*}{$\mathrm{H}_{2}$} & $15.4^{*}$ & $\mathrm{H}_{2} \mathrm{O}$ & $12.6^{*}$ & $(\mathrm{CN})_{2}$ & $13.6^{*}$ \\
\hline & & $\mathrm{H}_{2} \mathrm{O}_{2}$ & $11.1^{* *}$ & . No & 9.25 \\
\hline C & $11.3^{k \cdot k}$ & $\mathrm{CO}$ & $14.1^{\star}$ & $\mathrm{NO}_{2}$ & 9.8 \\
\hline $\mathrm{c}_{2}$ & $12.3^{*}$ & $\mathrm{CO}_{2}$ & $13.7^{*}$ & $\mathrm{~N}, 0$ & $12.9^{*}$ \\
\hline $\mathrm{CH}$ & $11.1^{* \star}$ & $\mathrm{HCO}$ & 9.9 & & \\
\hline $\mathrm{CH}_{2}$ & 10.7 & $\mathrm{H}_{2} \mathrm{CO}$ & 10.9 & $\mathrm{~s}$ & 10.4 \\
\hline $\mathrm{CH}_{3}$ & 9.8 & $\mathrm{CH}_{3} \mathrm{O}$ & 7.8 & $\varepsilon_{2}$ & 9.6 \\
\hline $\mathrm{CH}_{4}$ & $12.7^{*}$ & $\mathrm{CH}_{3} \mathrm{OH}$ & 10.8 & HS & 10.5 \\
\hline $\mathrm{C}_{2} \mathrm{H}_{2}$ & $11.4^{* \star}$ & $\mathrm{CH}_{3} \mathrm{CHO}$ & 10.2 & $\mathrm{H}_{2} \mathrm{~S}$ & 10.4 \\
\hline $\mathrm{C}_{2} \mathrm{H}_{4}$ & 10.45 & & & $\mathrm{CS}$ & $11.9^{*}$ \\
\hline $\mathrm{C}_{2} \mathrm{H}_{5}$ & 8.5 & $\mathbf{N}$ & $14.5^{*}$ & $\mathrm{Cs}_{2}$ & 10.1 \\
\hline \multirow[t]{2}{*}{$\mathrm{C}_{2} \mathrm{H}_{6}$} & $11.6^{*}$ & $\mathrm{~N}_{2}$ & $15.6^{*}$ & OCS & $11.2^{* *}$ \\
\hline & & NH & $13.1^{*}$ & so & 10.6 \\
\hline 0 & $13.62^{k}$ & $\mathrm{NH}_{2}$ & $11.4^{k *}$ & $\mathrm{SO}_{2}$ & $.12 .4^{*}$ \\
\hline $0_{2}$ & $12.01^{\star}$ & $\mathrm{NH}_{3}$ & 10.2 & & \\
\hline$o_{3}$ & $12.3^{\star}$ & $\mathrm{N}_{2} \mathrm{H}_{4}$ & 9 & & \\
\hline OII & $13.2^{*}$ & $\mathrm{CN}$ & $14.5^{*}$ & & \\
\hline
\end{tabular}

${ }^{a}$ Taken from NSRDS-NBS-26 (Ionization Potentials, Appearance Potentials, and Heats of Formation of Gaseous Positive Ions, 1969).

The effective short wavelength cutoff for LiF - $1080 \AA$ - corresponds to $11.5 \mathrm{eV}$. With this restriction, species with an IP less than about $(* *)$ $11.0 \mathrm{eV}$ will be ionized; those with an IP between $11.0 \mathrm{eV}$ and $11.5 \mathrm{eV}$
will be ionized weakly; and those with an IP greater than $11.5 \mathrm{eV}(*)$ will not be Ionized. 
NRCC DEVELOPIENTS AND THEORETTCT.ANS AD HOC GROUP

w.A. Lester, Jr.

\author{
National Resource for Computation in Chemistry* \\ Lawrence Berkeley Laboratory \\ University of California \\ Berkeley, CA 94720
}

An overview of recent activities at the NRCC including workshops; software, and research will be presented. In addition, a report of an informal meeting of quantum chemists and collision dynamicists .. held at Argonne National Laboratory on June 28, 1979 under the aegis of the NRCC will be given. Twelve combustion researchers from. Basic. Energy Sciences-supported groups at Ames, Argonne, Brookhaven, Lawrence Berkeley and Sandia Laboratories agreed to pursue a course. . of research jointly to elucidate the electronic structure and collision dynamics initially of the system of reactions involving one atom each of $\mathrm{C}, \mathrm{H}$ and $\mathrm{O}$. This effort is coordinated by the NRCC.

*The NRCC is funded jointly by the Basic Energy Sciences Division of the U.S. Department of Energy and the National Science Foundation. 


\title{
STUDY OF UNIMOLECULAR DISSOCIATION REACTIONS \\ AND RECOMBINATION REACTIONS
}

\author{
N.J. Brown \\ Lawrence Berekely Laboratory \\ University of California \\ Berkcley, $\mathrm{C} \Lambda 91720$
}

This research is concerned with formally extending unimolecular rate theory and applying the theory to important combustion reactions. This is important since unimolecular reactions play a crucial role in combustion initiation, fuel pyrolysis, radical quenching and pollutant formation and destruction mechanisms.

Current research is concerned with the study of bond fission reactions occurring near the high pressure limit. At this limit, the kinetics are first order and are dominated by intramolecular energy transfer. The starting point for this research is the statistical adiahatic channel model theory of Quack and Troe. Using this approach, one counts the number of adiabatic channel states constructed through the correlation of reactant and product, states. Adiabatic channel energies are constructed by a simple interpolation scheme. Rate coefficients $k(E, J)$ are then determined by ratioing the number of open channel states to the density of states of the reactant molecule. Calculations are currently being performed on the molecules $\mathrm{NO}_{2}$ and $\mathrm{CH}_{4}$ with the goal of obtaining dissociation rate coefficients for these molecules which show the proper dependence on total rotational quantum number. The parameterization requisite for determining the channel energies is under investigation. 
THEORETICAL FORS CALCULATIONS OF COMBUSTION REACTIONS

Klaus Ruedenberg

Ames Laboratory

Iowa State University.

Ames, Iowa 50011

Theoretical calculations of combustion reactions offer two advantages: individual reaction channels can be studied without interference from competing processes, and short-lived transition states can be examined in detail. The resulting information, while valuable for the experimental search, is difficult to obtain experimentally. The difficulties in the theoretical description arise from the fact that combustion reactions have large reaction energies as well as high activation barriers. Electronic rearrangement with such characteristics involve essential changes in configurational mixing as well as substantive orbital deformations. Recently, effective descriptions have been developed through wave functions in the "full optimized reaction space" which include al1 configurations with all spatial and all spin couplings resulting from all molecule-adapted atomic valence shell orbitals which significantly influence the rearrangement. Optimal wave functions have been obtained by novel and completely general MCSCF methods. Energy barriers have been determined for the dissociation of ethylene, for the dissociation of dionctanc to formaldehyde, the formation of dioxirane from oxygen and methylene, the isomerization of nitrosyl hydride, and other reactions. Another research group has used our method and computer program to investigate the reaction of hydrogen with the hydroxyl radical. We are initiating a study of the isomerization of the HCO radical. 
CHEMICAL SPECIES AND REACTION INVOLVED IN COMBUSTION

\author{
Thom. H. Dunning, Jr., Stephen P. Walch, \\ Albert F. Wagner, George C. Schatz ${ }^{\dagger}$ and Joel M. Bowmant†
}
Thcorctioal Chemistry Group
Chomietry Division

Argonne National Laboratory

Argonne, Illinois 60439

The objective of our research program is the theoretical characterization of the chemical species and elementary chemical processes (reaction, chemi-ionization, charge transfer, etc.) involved in the oxidation of hydrogen and simple hydrocarbon fuels. This program combines the ab initio calculation of the potential energy surfaces of chemical reactions with dynamical studies on the computed, or other realistic, surfaces. $\mathrm{Ab}$ initio studies of the structure and spectra of intermediate, chemically unstable, species are also undertaken.

\title{
I. Oxidation of Hydrogen
}

Reactions involved in the oxidation of hydrogen which are currently under study include

$$
\begin{aligned}
\mathrm{O}+\mathrm{H}_{2} & \rightarrow \mathrm{OI}+\mathrm{H} \\
\mathrm{OH}+\mathrm{H}_{2} & \rightarrow \mathrm{H}_{2} \mathrm{O}+\mathrm{H} \\
\mathrm{H}+\mathrm{O}_{2} & \rightarrow \mathrm{OH}+\mathrm{O}
\end{aligned}
$$

Calculations for limited regions of the potential energy surfaces of reaction (1) - (2) have been completed. For these reactions the calculations predict activation energies of 9.7 and 5.9 $\mathrm{kcal} / \mathrm{mole}$, respectively; these are to be compared

\footnotetext{
† Consultant. Permanent address: Department of. Chemistry, Northwestern University, Evanston, Illinois 60201

${ }^{+}$Consultant. Permanent address: Department of Chemistry, Illinois Institute of Technology, Chicago, Illinois 60616
} 
to experimentally derived values of $8-10$ (1) and 4-6 (2) $\mathrm{kcals} / \mathrm{mole}$. Calculation of the rates of these reactions on the computed potential surfaces are in substantial agreement with representative experimental measurements over the temperature range from $300-2000^{\circ} \mathrm{K}$.

Calculations on reaction (3), and the HOO, intermediate, are currently underway.

\section{Oxidation of Methane}

Reactions involved in the oxidation of methane which are presently under study include

$$
\begin{aligned}
& \mathrm{O}+\mathrm{CH}_{4} \rightarrow \mathrm{OH}+\mathrm{CH}_{3} \\
& \mathrm{H}+\mathrm{CH}_{4} \rightarrow \mathrm{H}_{2}+\mathrm{CH}_{3}
\end{aligned}
$$

and the family of reactions

$$
\mathrm{CH}_{\mathrm{n}}+\mathrm{O} \rightarrow
$$

Calculations over limited portions of the potential energy surfaces of reactions (4)-(5) have been completed. Again, the calculated rates of these reactions are in substantial agreement with representative experimental measurements over a wide temperature range.

Our preliminary studies of reaction (6), a joint project with AL, BNL, SLL and LBL, will be reported by $W$. A. Lester, Jr. of the National Resource of Computation in Chemistry. 
PROPERTIES OF INTERMEDIATE COMPLEXES IN REACTIVE COLLISIONS

OF $O\left({ }^{1} D\right)$ WITH $H_{2}, \mathrm{HD}$, AND $D_{2}$

James T. Muckerman

Department of Chemistry

Brookheven National Laboratory

Jpton, NY 11973

Monte Carlo quasiclassical trajectory calculations of collisions of $O\left({ }^{1} D\right)$ with $H_{2}, H D$, and $D_{2}$ using a valence bond diatomics-1n-molecules potential energy surface have provided information on the lifetimes of $\mathrm{H}_{2} \mathrm{O}$, $\mathrm{HDO}$, and $\mathrm{D}_{2} \mathrm{O}$ intermediate complexes, the degree of vibrational energy randomization occurring during the lifetimes of these complexes, and the intramolecular isotope effect (branching rat10) in the "unimolecular" decomposition of the HDO complex. Analysis of the solid-angle differential cross section in terms of the osculating complex model yields a lifetime relative to the rotational period of the couplex. A surprisal analysis of the product vibrational state distribution monitors the degree of vibrational energy randomization in the complex.

A computer-animated movie of randomly selected trajectories involving complexes is useful in constructing a "model" of the geometries of the "tight complex" and the "transition state" for decomposition. 
INTERACTIONS BETWEEN HYDROCARBONS AND TRANSITION METAL CLUSTERS

\author{
Marshal1 D. Newton \\ Department of Chemistry \\ Brookhaven National Laboratory \\ Upton, NY 11973
}

A complete understanding of the kinetics of hydrocarbon combustion requires consideration of potentially important heterogeneous catalytic roles to be played by transition metals. It is clearly desirable to elucidate the structural and electronic aspects of the associated chemisorptive interactions. The techniques of $a b$ initio molecular quantum mechanics, especially as facilitated by effective potentials for inner shell electrons, make feasible theoretical studies of small transition metal clusters and their interactions with species such as hydrogen, oxygen, carbon monoxide, and ethylene. We shall outline recent results of prototype studies involving nickel clusters and cluster complexes, emphasizing the details of specific electronic states, especially as they bear on the nature of metal-metal and chemisorptive binding. The reported $\underline{a b}$ initio results are based on various self consistent field ( $S C F$ ) and configuration interaction (CI) Formilisms. 
THEORETICAL STUDIES IN HETEROGENEOUS COMBUSTION

C. K. Law

Northwestern University

Evanston, Illinois 60201

The aim of this research is to first understand the vaporization/ combustion characteristics of single fuel droplets in environments simulating the spray interior, and then to model the combustion of spray jets. So far we have accomplished the first task. Results from the following two specific projecrs w111 be presenled.

(1) Gas-Phase Quasi-Steadiness and Fuel Vapor Accumulation Effects in Droplet Burning -- The classical $\mathrm{d}^{2}$-law assumes that the instantaneous vaporization rate at the droplet surface is equal to that of fuel consumption at the flame, hence neglecting the substantial amount of fuel vapor accumulated in the inner region to the flame. A theory has been formulated allowing for this accumulation process. Its predictions have also been verified experimentally. It is emphasized that adoption of the $\mathrm{d}^{2}-1$ aw in spray modeling may lead to significant errors in estimating the chemical heat release rate.

(2) An Ignition Criterion for Droplets in Sprays -- The 1gnitability of a fuel droplet in a reactive oxygen/fuel-vapor/inert environment simulating the spray interior has been analyzed. A set of universal ignition Damköhler number curves have been numerically generated and subsequently fitted. to yield an explicit ignition criterion suitable for incorporation into spray modeling.

During the coming year efforts will be devoted to modeling vapuri= zation of spray jets. 


\section{SENSITIVITY ANALYSIS IN \\ CHEMICAL KINETICS AND QUANTUM DYNAMICS}

Herschel Rabitz

Princeton University

Many physical phenomena require complex models or dynamics for their description. For example, in chemical kinetics many species and reactions can enter even in the simplest combustion system. The underlying collision dynamics of just two reaction molecules of ten requires a complex model, since the appropriate Schrobdinger equation will require an intricate intermolecular potential. A central concern in these types of problems is how sensitive the calculated observables are with respect to the input information (e.g., rate constants in kinetics, and the potential in quantum dynamics). This concern is particularly important since the input information (often expressed as parameters) may be imprecisely known. Furthermore, this typical lack of quantitative information on system parameters leads to the question of what experiments would be appropriate to pin then down. These questions can all be conveniently addressed in the framework of sensitivity analysis. We have been developing efficient new techniques to calculate system sensitivities $\frac{\partial O_{i}}{\partial \alpha_{r}}$ where $o_{i}$ is the $i$-th observable and $\alpha_{r}$ is the $r$-th system parameter. In a similar fashion, correlation sensitivities $\frac{\partial \alpha_{r}}{\partial \alpha_{p}}$ can be considered. These latter sensitivities have an important bearing on the uniqueness of a given model for producing a particular set of laboratory observationo.

A general algorithm has been written to perform sensitivity calculations in chemical kinetics. Recently, application of this program was made to a detailed combustion model of $\mathrm{H}_{2}+\mathrm{O}_{2}$ near.the explosion limits. In a 
separate study extensive sensitivity calculations were performed on rotationally and vibrationally inelastic molecular collisions to study the role of intermolecular potential structure. Particularly interesting correlations between system parameters were found. Present work is focusing on the development of the theory to treat continuous functional variations, rather than discrete parameters, for both kinetics and quantum dynamics. 
NATIONAL THEORETICAL EFFORT ON COMBUSTION

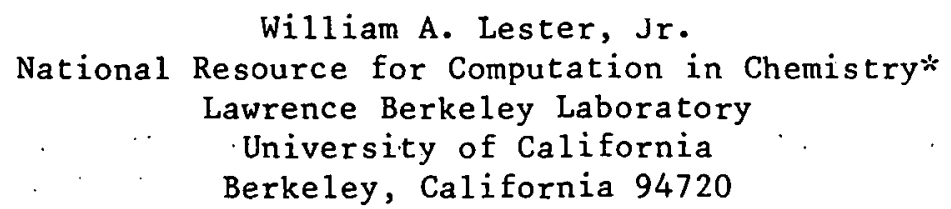

A collaborative research effort on the chemistry of combustion has been launched by an association of scientists at some of the nation's leading national laboratories and universities. The participants have agreed to pursue a course of research to elucidate the electronic structure and collision dynamics of a system of reactions involving carbon, hydrogen, and oxygen. This extensive and intensive theoretical examination of a processs which is basic to the production energy will be coordinated by the National Resource for Computation in Chemistry (NRCC).

The present meeting is the second the scientists have held to date. The first one took place on June 28,1979 at Argonne National Laboratory. At these meetings, the issues explored included:

- What reactions, or classes of reactions, are of general importance in combustion systems?

- What can theoretical studies contribute to the understanding of these reactions?

- How can the participants organize their research programs to ensure that these problems are properly addressed?

${ }^{*}$ The NRCC is funded jointly by the Basic Energy Sciences Division of the United States Department of Energy and the National Science Foundation. 
As a result of the first meeting the participating scientists resolved to study reaction prototypes, such as $\mathrm{CH}_{n}+0$, in their. search for general principles of importance in all hydrucarbun processes. The inicial project chosen was

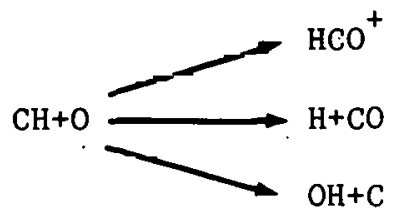

The $\mathrm{CH}+\mathrm{O}$ reaction is of unusual importance because channel ( 1 ) is presumed to be a dominant pathway for information in hydrocarbon flames, and channel (2) is postulated to be source of highly vibrationally excited $\mathrm{CU}$ in acetylene flames.

Collaborating in the proglam are fourteen quantum chemists and collision theorists supported by Basic Energy Sciences at Argonne, Brookhaven, Ames, Sandia Livermore and Lawrence Berkeley Laboratories, Princeton University, and the University of California, Berkeley. 


\section{COMBUSTION KINETICS DATA EVALUATION}

W. Tsang

National Bureau of Standards

Washington D. C. 20234.

The aim of this work is to develop a chemical kinetic data base for hydrocarbon combustion based on elementary single step chemical processes. The first step; compilation of all previous recommendations as well as the experimental results bridging the gap between the earlier reviews and 1978 will be published shortly. The evaluation of the data on methane pyrolysis has been substantially completed and will be discussed at this meeting.

The general characteristic of the kinetic data on hydrocarbon oxidation is that of a few reactions with many measurements, other reactions with no measurements and many measurements which are not readily transferable into elementary rate data. During the past year we have examined the data on methane and ethane pyrolysis which contain information on the product distribution $\left(\mathrm{CH}_{4} \mathrm{C}_{2} \mathrm{H}_{6}, \mathrm{C}_{2} \mathrm{H}_{4}, \mathrm{C}_{2} \mathrm{H}_{2}, \mathrm{H}_{2}\right)$. This covers the temperature region 900-1800K and involve shock tube, and static experiments. Through the use of chemical kinetic modeling a general mechanism which can give a satisfactory quantitative explanation for all the results has been derived. Rate expressions for a variety of metathesis reactions involving methyl and hydrogen abstractions have been determined and compared with the BEBO estimates. The possibility of vinyl and similar type reactions as. important gas phase percusors to carbon formation and the usefulness of modeling as a kinetic tool will be discussed. 


\title{
HIGH-TEMPERATURE PHOTOCHEMISTRY (HTP) STUDIES \\ OF ISOLATED ELEMENTARY COMBUSTION REACTIONS
}

\author{
Arthur Fontijn and William Felder \\ AeroChem Research Laboratories, Inc. \\ P.0. Box 12, Princeton, New Jersey 08540
}

The objectives of work under contract EG-77-C-02-4169 are to develop and use a single kinetic technique to provide rate coefficient data over wide temperature ranges. Specifically, such $k(T)$ are being measured for fossil fuel combustion reactions of importance either in determining the performance of combustion devices and engines or in pollutant formation processes. Such data have been scarce and usually covered only limited temperature ranges. We have now developed the HTP technique which allows obtaining data from room temperature (or below) to about $1800 \mathrm{~K}$ for such reactions. HTP applies the HighTemperature Fast-Flow Reactor (HTFFR) technology, which we developed for studies of reactions of thermally stable species such as metal atoms and monoxides, to pulsed/flash photolysis resonance fluorescence/absorption methodology. The latter had previously been widely used for kinetic measurements on hydrocarbon combustion intermediates at low temperatures.

The reaction

$$
\mathrm{O}+\mathrm{CH}_{4} \rightarrow \mathrm{OH}+\mathrm{CH}_{3}
$$

has been used to develop the HTP technique and was selected because (i) it is one ot the best studied elementary hydrocarbon oxidation steeps and (11) "good agreement" between' low and high temperature data exists. It thus provides a good benchmark for HTP results. Previous experimental data on $k_{1}(T)$ fall into two groups, those obtained at $1200-2250 \mathrm{~K}$ in shock tubes and at 250-950 $\mathrm{K}$ from flow tube, stirred reactor, flash photolysis resonance fluorescence, and flame ignition studies. The present data (400-1600 K) overlap these ranges and show a slightly curved Arrhenius plot, generally in satisfactory agreement with the more reliable earlier studies and transition state theory. At high temperatures, the data fall between the shock tube measurements of Dean and Kistiakowski and those of Roth and Just, agreeing somewhat better with the former.

Future research plans include using HTP to determine $k(T)$ of the $\mathrm{C}_{6} \mathrm{H}_{6} / \mathrm{OH}$, $\mathrm{CH}_{9} / \mathrm{O}$, and $\mathrm{CH}_{3} / \mathrm{O}_{2}$ reactions. 


\title{
COMBUSTION STUDIES OF ALTERNATIVE FUELS
}

\author{
R. Bruce Klemm \\ Department of Energy and Environment \\ Brookhaven National Laboratory \\ Upton, New York 11973
}

The primary aim of this project is to investigate the combustion chemistry and kinetics of alternative fuels. The kinetics of pollutant formation processes in combustion systems is included within this scope." The project is divided into two parts, as before. A kinetics phase is devoted to making absolute measurements of bimolecular rate constants for relevant atom-molecule reactions utilizing both falsh photolysis and discharge flow techniques. Over the last year, however, the engine studies phase was terminated and replaced by a flame probe experiment that is associated with a photoionization mass spectrometric study on the National Synchrotron Light Source. The goals and status of this effort are discussed elsewhere in this program.

Progress in the kinetics laboratory includes the completion of a study of the reaction of $O\left({ }^{3} \mathrm{P}\right)$ with ethylene using two experimental methods. The results appear to reconcile a discrepancy that had existed between data. obtained from flow tube studies and that from a flash photolysis experiment. In addition, a quartz flow tube was installed on the discharge flow-resonance fluorescence apparatus so that experiments could be performed at temperatures approaching 1200K. The reaction of atomic oxygen with methane has been studied in this Improved system and absolute rate constants, including some from the flash photolysis experiment, were obtained over the temperature range $474 \mathrm{~K}$ to 1156K. No curvature can be seen in an Arrhenius plot of the data, within the experimental uncertainty. The rate expression derived is:

$$
k(T)=(2.15 \pm 0.30) \times 10^{-10} \exp (-10872 \pm 192 / \mathrm{RT}) \mathrm{cm}^{3} \mathrm{molec}^{-1} \mathrm{~s}^{-1}
$$

This result can be interpreted either by a simple collision model, $\left[\rho Z_{L J} \exp \left(-E_{a} / R T\right)\right]$; or using a three parameter fit, $\left[A^{\prime} T^{1 / 2} \exp \left(-E_{a}{ }^{\prime} / R T\right)\right]$, and in either case an extrapolation of these results correlates well with the data of Roth and Just at 1500-2250K. 
A KINETIC STUDY OF RADICAL-AROMATIC HYDROCARBON REACTIONS

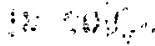
it: $: \cdots$
F. P. Tully and A. R. Ravishankara Molecular Sciences Group
Engineering Experiment Station Georgia Institute of Technology Atlanta, Georgia 30332

\begin{abstract}
Utilizing the technique of tlash photolysis-resonance fluorescence in conjunction with both low and high temperature slow-flow reacturs, absolute rate constants have been measured for the reactions of the hydroxyl radical with benzene, toluene and certain of their deuterated analogs. Measurements have been made in the temperature and pressure intervals 230-815K and 10-200 Torr, respectively; $\mathrm{He}, \mathrm{Ar}$ and $\mathrm{SF}_{6}$ have been used as diluent gases. Evidence for the importance of three reaction channels, $\mathrm{OH}$ addition to the aromatic ring and $\mathrm{H}$-atom abstraction from both ring and side-chain carbon atoms, has been obtained. Results to date will be reviewed.
\end{abstract}




\title{
STUDIES OF COMBUSTION KINETICS AND MECHANISMS
}

\author{
David Gutman \\ Department of Chemistry \\ Illinois Institute of Technology \\ Chicago, Illinois 60616
}

The purpose of this research is to develop a new method of generating polyatomic free radicals under controlled conditions, and to use the method to study those reactions they undergo which are important in combustion processes. The rate constants and mechanistic information obtained will be of value in the modeling of combustion systems.

The method involves the use of an unfocused, pilsed, $\mathrm{CO}_{2}$ TEA laser to dissociate free-radical precursors in a fast-flow reactor. A photoionization mass spectrometer is used to dynamically monitor concentration profiles of both reactants and products. The experimental facility is now constructed and several design parameters have been varied to achieve optimum performance including laser power and beam focusing, reactor shape and flow velocities, special differental pumping in the mass spectrometer; and gas sampling cone geometries. The laserinduced decomposition of the radical precursors is now homogeneous throughout the reactor and amounts to up to 20 percent in each laser pulse depending on Taser power.

Expected behavior has now been achieved using precursors which do not produce free radicals indicating that the facility is ready for the proposed studies. Experiments are now in progress to generate alkoxyl $\left(\mathrm{R} 0^{\circ}\right)$ free radicals from nitrites and nitrates and to study their reactions with $\mathrm{O}_{2}$, NO, and organic moleculeș. 
Ralph Livingston and Henry Zeldes

Chemistry Division, Oak Ridge National Laboratory

Oak Ridge, Tennessee 37830

Electron spin resonance equipment has been developed for directly observing labile free radicals that are present at high temperalures. A pressurized fluid is heated as it slowly flows through the microwave cavity of the spectrometer. Temperatures to $560^{\circ} \mathrm{C}$ and pressures to $2000 \mathrm{psi}$ are used. Studies have centered largely on aromatic hydrocarbons, and benzylic radicals are most often observed. Radicals are identified from well resolved hyperfine structure. Compounds thus far studied include indene, bibenzyl, ethylbenzene, p-cymene, tetraphenylethane, n-propyibenzene, and cumene. Cumene forms cumyl pyrolytic.ally, arid is now under detailed study. Air saturated cumene gives a small yield of cumyl at $350^{\circ} \mathrm{C}$. At $560^{\circ} \mathrm{C}$ much higher yields of cumyl are obtained by reaction pathways not involving oxygen. The principal pathway appears to be the pyrolytic decomposition of cumene to form phenylethyl and methyl with these radicals subsequently abstracting hydrogen from cumene. 
FLASH PHOTOLYSIS STUDIES : : REACTIONS

OF $\mathrm{CH}_{3}, \mathrm{HCO}, \mathrm{AND} \mathrm{HO} 2$

C. J. Hochanadel and T. J. Sworski

Chemistry Division, Oak Ridge National Laboratory

Oak Ridge, Tennessee 37830

\begin{abstract}
Absolute rate constants for several reactions of $\mathrm{CH}_{3}, \mathrm{HCO}$, and $\mathrm{HO}_{2}$ have been evaluated. The radicals were produced by the photodissociation of $\mathrm{H}_{2} \mathrm{O}$ in the presence of $\mathrm{CH}_{4}, \mathrm{CO}$, and $\mathrm{O}_{2}$ respectively, and kinetic measurements utilized the free radical absorptions at 216, 230, and $220 \mathrm{~nm}$ respectively. Kinetic parameters were adjusted by the method of least squares to fit theoretical curves to the experimental data, and error limits were established by sensitivity analysis. Previously reported values for $\varepsilon\left(\mathrm{CH}_{3}\right)=9000 \pm 800 \mathrm{M}^{-1} \mathrm{~cm}^{-1}$, and $\mathrm{k}_{3}\left(\mathrm{CH}_{3}+\mathrm{CH}_{3}\right)=$ $3.1 \pm 0.6 \times 10^{10} \mathrm{M}^{-1} \mathrm{~s}^{-1}$ were used in evaluating $\mathrm{k}_{4}, \mathrm{k}_{8}, \mathrm{k}_{2}, \mathrm{k}_{5}$, and the amount of water dissociated by the flash in the $\mathrm{H}_{2} \mathrm{O}+\mathrm{CH}_{4}$ system. This latter value was then used as an "actinometer" in the $\mathrm{H}_{2} \mathrm{O}+\mathrm{CO}$ and $\mathrm{H}_{2} \mathrm{O}+\mathrm{O}_{2}$ systems in order to evaluate the other rate constants listed in the table. The value for $\varepsilon(H C O)$ at the $230 \mathrm{~nm}$ maximum was $941 \pm 114 \mathrm{M}^{-1} \mathrm{~cm}^{-1}$, and for $\mathrm{HO}_{2}$ it was $10.32 \pm 57 \mathrm{M}^{-1} \mathrm{~cm}^{-1}$ at the $205 \mathrm{~nm}$ maximum and $889 \pm 49 \mathrm{M}^{-1} \mathrm{~cm}^{-1}$ at $220 \mathrm{~nm}$. Our results indicate that $\mathrm{k}_{4}$ and $\mathrm{k}_{8}$ are at the second order limit for one atmosphere of $\mathrm{CH}_{4}$. The values for $\mathrm{k}_{16}$ and $\mathrm{k}_{17}$ are somewhat less than values we had reported in 1972; the difference is due chiefly to a difference in actinometry. Our current value for $\varepsilon\left(\mathrm{HO}_{2}\right)$ is close to that reported by Paukert and Johnston. The value for $k_{16}$ is in the presence of 20 Torr of $\mathrm{H}_{2} \mathrm{O}$. The value for $\mathrm{k}_{17}$ is $\sim 0.6$ of our previous value, but is still a factor of 23.8 larger than a recent value by Hack, Preuss, and Wagner.
\end{abstract}
4) $\mathrm{H}+\mathrm{CH}_{3} \stackrel{\mathrm{M}}{\rightarrow} \mathrm{CH}_{4}$
$1.2 \pm 0.3 \times 10^{11} \mathrm{M}^{-1} \mathrm{~s}^{-1}$
8) $\mathrm{OH}+\mathrm{CH}_{3} \stackrel{\mathrm{M}}{\rightarrow}$ Products
$5.6 \pm 1.5 \times 10^{10} \mathrm{~m}^{-1} \mathrm{~s}^{-1}$
2) $\mathrm{OH}+\mathrm{CH}_{4} \rightarrow \mathrm{CH}_{3}+\mathrm{H}_{2} \mathrm{O}$
$4.2 \pm 0.4 \times 10^{6} \mathrm{M}^{-1} \mathrm{~s}^{-1}$
5) $\mathrm{OH}+\mathrm{H}_{2} \Rightarrow \mathrm{H}+\mathrm{H}_{2} \mathrm{O}$
$5.1 \pm 1.1 \times 10^{6} \mathrm{M}^{-1} \mathrm{~s}^{-1}$
13) $\mathrm{H}+\mathrm{CO} \stackrel{\mathrm{M}}{\rightarrow} \mathrm{HCO}$
a) $(\mathrm{M}=\mathrm{CO})$
$3.6 \pm 0.8 \times 10^{7} \mathrm{M}^{-2} \mathrm{~s}^{-1}$
b) $\left(\mathrm{M}-\mathrm{H}_{2}\right)$
$3.8 \pm 0.2 \times 10^{7} \mathrm{M}^{-2} \mathrm{~s}^{-1}$
c) $\left(\mathrm{M}=\mathrm{CH}_{4}\right)$
$5.8 \pm 0.4 \times 10^{7} \mathrm{M}^{-2} \mathrm{~s}^{-1}$
14) $\mathrm{HCO}+\mathrm{HCO} \rightarrow$ Products
$1.4 \pm 0.3 \times 10^{10} \mathrm{~m}^{-1} \mathrm{~s}^{-1}$
15) $\mathrm{H}+\mathrm{HCO} \rightarrow \mathrm{H}_{2}+\mathrm{CO}$
$6.9 \pm 1.4 \times 10^{10} \mathrm{M}^{-1} \mathrm{~s}^{-1}$
16) $\mathrm{HO}_{2}+\mathrm{HO}_{2} \rightarrow \mathrm{H}_{2} \mathrm{O}_{2}+\mathrm{O}_{2}$
$4.0 \pm 0.3 \times 10^{9} \mathrm{M}^{-1} \mathrm{~s}^{-1}$
17) $\mathrm{HO}_{2}+\mathrm{OH} \rightarrow \mathrm{H}_{2} \mathrm{O}+\mathrm{O}_{2}$
$6.8 \pm 1.3 \times 10^{10} \mathrm{M}^{-1} \mathrm{~s}^{-1}$

NO ORAL PRESENTATION WAS MADE. 
HIGH RESOLUTION PHOTOIONIZATION STUDIES OF SOME SIMPLE MOLECULES NEAR THE THRESHOLDS

\author{
C. $\mathrm{Y}, \mathrm{Ng}$ \\ Ames Laboratory and Department of Chemistry \\ Iowa Sta.te. TTniversity \\ Ames, IA 50011
}

A molecular beam photoionization apparatus which consists of a versatile crossed molecular beam production system, a differentially pumped windowles $3-\mathrm{m}$ vacuum ultraviolet monochromator, and a quadrupole mass spectrometer has been constructed and successfully brought into operation. Photoionization experiments carried out with this apparatus indicates a substantial improvement in performance as compared to the 1-m apparatus. ${ }^{1}$

The photoionization efficiency curve of NO near the threshold has been obtained with a photon bandwldth of $0.14 \AA$. Sincc this resolution is a factor of six greater than that previously used to investigate this system ${ }^{(1)}$, much more detailed structures are rodolved, Comparing the photninniration rcoulte with the recent. absorption experiments by Miecher ${ }^{2,3}$, resonances can be assign= ed lo autoiunizing ns, np, nd, and nf Rydberg lèvels. Althnugh the strong peaks observed in this work can be attributed to $\Delta V=-1$ transitions in the vibrational autoionization process, resonances due to $\Delta \mathrm{V}<-1$ transitions are also clearly evident.

Attempts have been made to investigate the efficiency in relaxation of NO from the ${ }^{2} \Pi_{3 / 2}$ to ${ }^{2} \Pi_{1 / 2}$ during free jet expansion 
by examining the photoion yield curves of $\mathrm{NO}$ at $150^{\circ} \mathrm{K}, 290^{\circ} \mathrm{K}$ and $450^{\circ} \mathrm{K}$. The implication of the se spectra on the ionization potential of NO will be discussed.

Preliminary photoionization studies of $\mathrm{C}_{2} \mathrm{H}_{2}$ and $\mathrm{CS}_{2}$ will also be presented.

\section{References}

(1) C. Y. Ng, B. H. Mahan, and Y. T. Lee, J. Chem. Phys. 65, 1965 (1976)。

(2) E. Miescher and F. Alberti, J。 of Phys, and Chem. Ref. data, $\underline{5}, 309$ (1976).

(3) E. Miescher and Y. T. Lee, J. Chem. Phys. 68, 2753 (1978). 


\section{THE CROSSED BEAM STUDIES ON REACTIONS OF $O\left({ }^{3} P\right)$ AND $O\left({ }^{1} D\right)$}

Richard J. Buss and Yuan T. Lee

Materials and Molecular Research Division, Lawrence Berkeley Laboratory and Department of Chemistry, University of California

Berkeley, California 94720

- The development of high intensity supersonic $O\left({ }^{3} P\right)$ and $O\left({ }^{l} D\right)$ beam sources now opens the way to obtaining a detailed knowledge of many important elementary chemical reactions involved in combustion and atmospheric processes. Reliable information on the mechanism of these elementary reactions is still lacking mainiy because of the complication caused by the subsequent reaction of radical molecules formed in a bulk study and the difficulty of identifying vibrationally excited radical molecules by mass spectrometry due to fragmentation in the ionizer. In order to understand the mechanism and the dynamics of the reaction of oxygen atoms, we have employed crossed molecular beams to study the primary products under single collision conditions to eliminate the possibility of secondary reactions and, using kinematic and energetic constraints on the systems, we have obtained positive identification of reaction products and other information unobtainable in bulk phase studies. The reactions studied recently include $\mathrm{O}\left({ }^{3} \mathrm{P}\right)+\mathrm{C}_{6} \mathrm{H}_{6}, \mathrm{C}_{6} \mathrm{D}_{6}$ as well as $\mathrm{O}\left({ }^{1} \mathrm{D}\right)+\mathrm{H}_{2}, \mathrm{D}_{2}$ and $\mathrm{CH}_{4}$.

In the reaction of $O\left({ }^{3} \mathrm{P}\right)$ with benzene, we have identified two reaction pathways :

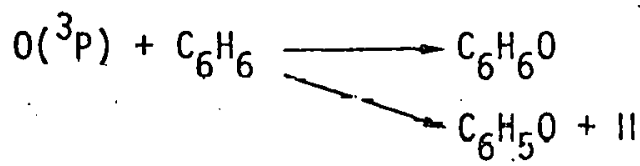

The products can be distinguished as arising from separate primary reactions by the difference in angular and velocity distributions of the detected masses. The stabilization of the phenol is attributed to an eiectronic curve crossing from the triplet to the singlet state.

With the development of a supersonic $0\left({ }^{1} D\right)$ beam source we have begun to investigate the reactions of this extremely reactive species in the single collision environment. The angular and velocity distributions of $O H$ and $O D$ product from the reaction with $\mathrm{H}_{2}$ and $\mathrm{D}_{2}$ have been used to establish the reaction mechanism and to obtain product energy distributions. There has been confusion concerning the primary products of the reaction of $\left.\mathrm{O}^{l} \mathrm{D}\right)$ with $\mathrm{CH}_{4}$, which arises trom the difficulty inherent to lhe study of highly reactive radicals in bulk phase. We have been able to identify $\mathrm{CH}_{3} \mathrm{O}$ as a primary dissociation product of the insertion reaction forming $\mathrm{CH}_{3} \mathrm{OH}^{*}$ intermediate, and eliminate the possibility that $\mathrm{CH}_{2} \mathrm{O}$ is a major product by measurement of product velocity distributions. 
LOW ENERGY ION-MOLECULE REACTIONS AND. CHEMIIONIZATION KINETICS

James i. Farrar

University of Rochester.

Our research in the past year has focused upon low energy proton transfer and charge exchange reactions of $\mathrm{H}_{2}{ }^{+}$with atoms and diatomic molecules. We have completed a detailed study' of the system $\mathrm{H}_{2}^{+}(\mathrm{CO}, \mathrm{H}) \mathrm{HCO}^{+}$in the relative energy range from $0.74 \mathrm{eV}$ to $9.25 \mathrm{EV}$. Detailed energy and angular distributions of the $\mathrm{HCO}^{+}$product have been determined and are found to be in qualitative agreement with the Elastic spectator stripping model. We have rationalized the reactive and charge transfer behavior of this system in terms of electronic state correla- - . tion diagrams and have found that conical intersections of $\mathrm{H}_{2} \mathrm{CO}^{+}$surfaces as $\mathrm{H}_{2}^{+}$approaches $\mathrm{CO}$ are cruciali in understanding the reactions:

We have also begun detailed studies of the $\mathrm{H}_{2}^{+}+\mathrm{Ar} ; \mathrm{He}$, $\mathrm{Ne}, \mathrm{O}_{2}$, and $\mathrm{N}_{2}$ systems; we expect to present differential cross sections for the first two of these reactions. 
INFRARED LASER INDUCED "PHOTOCHEMISTRY

\author{
W. A. Guillory \\ University of Utah
}

The kinetics of flames and combustion processes, by nature, are very complex, but the behavior of these systems may be reasonably described in terms of rate equations which consider energy transfer as well as chemical reaction. Intil recently, it was practically impossible to characterize the elementary physical and chemical processes occurring in these systems. The phenomenon of infrared multiphuturn absorption, subsequently leading to ground and excited state fragmentation, simulates non-equilibrium processes occurring in flames and combustion reactions. Using laser sources as a probe of the reaction zone, highly sensitive time and wavelength resolved spectroscopy allow detailed determination of the mechanism and energetics of a given system. Discussion of vibrational energy transfer and dispersion of propynal ( $\mathrm{HC}=\mathrm{C}-\mathrm{C}_{\mathrm{H}}^{-}$) down to $5 \mathrm{mtor}$ will be presented. Preliminary studies of state-to-state reactions of $\mathrm{C}_{3}$ witti $\mathrm{NO}, \mathrm{O}_{2}$, and $\mathrm{CH}_{4}$ and the initi.a] steps in the in laser-induced combustion of $\mathrm{C}_{2} \mathrm{H}_{4}$. in the presence of $\mathrm{O}_{2}$, will also be discussed. 
Our objective is to make absolute measurements of the rates of energy-transfer processes involving highly vibrationally excited organic molecules in gas-phase systems that are not complicated by chemical reactions. Such energy-transfer processes play a role in the pyrolysis of organic compounds in combustion systems and can also be major factors in laser-induced chemistry and isotope separation.

Azulene has been used in these studies because (1) it has a convenient absorption band in the visible, and (2) it undergoes internal conversion within $\sim 2$ psec following excitation. Thus, laser excitation permi.ts the preparation of an ensemble of vibrationally excited azulene with $17000 \mathrm{~cm}^{-1}$. of internal energy . $\because \quad \therefore$.

In the first phase of this project, the technique of Time-Dependent-ThermalLensing has been used to measure the rate of appearance of the excitation energy in the translational degrees of freedom. A lower limit to this rate has been measired that indicates llid a major traction of the energy appears in translation after only one collision.

We are now attempting to measure $V-V$ transfer rates by observing infraxed fluorescence from azulene and measuring its spectral distribution and temporal behavior in the presence of collider gases.

\footnotetext{
† International Fellow; present address, Ben Gurion University of the Negev P.O. Box 65.3, Beer-Sheva, Israel.
} 
FLAME RESEARCH

M. A. Gusinow

Sandia Laboratories

The work to be discussed is concerned with experimental and theoretical flame research. Particular emphasis has been given to the utilization of laser diagnostics to obtain spatially resolved measuremenls of radical concentrations and flame temperatures.

A study utilizing laser absorption/fluorescence to monitor [OH] in an: atmospheric $\mathrm{CH}_{4}$ /air flat flame has been completed. A comparison of experiment and theory. will be given.

Another aspect of atmospheric flame research to be described utilizes spontaneous Raman scattering to give Raman spectra of $\mathrm{CO}_{2}$ and $\mathrm{H}_{2} \mathrm{O}$. The result of this work is that gas temperatures can be accurately deduced from these spectra.

Theoretical considerations have elucidated important chemical mechansims in $\mathrm{NH}_{3} / \mathrm{n}_{2}$ flames. The role of these mechanisms have been ascertained at both atmospheric and low pressure conditions. 


\section{PROGRAMS AT THE \\ COMBUSTION RESEARCH FACILITY}

D. L. Hartley

Sandia Laboratories

The Combustion Sciences Department at Sandia Laboratories, Livermore, California, is responsible for conducting a broad range of combustion studies, both basic and applied, and is responsible for the operation of the DOE Combustion Research Facility. The basic research programs are funded by the Division of Basic Energy Sciences, DOE, and include flame research, diagnostic research and Facility management. The flame research projects emphasize the application of laser diagnostics, particularly Raman and fluorescence spectroscopy. to the study of fundamental processes in low pressure and in atmospheric laminar and turbulent flames. The diagnostic research projects have emphasized the development and improvement of CARS, SARS and other advanced methods. The diagnostic development includes a high power, frequency doubled YAG laser for Raman diagnostics and a high power tunable dye lasar for general diagnostics.

The applied research projects include i.c. engine combustion, which has emphasized joint industry research on homogeneous, stratified charge and diesel engines. Projects have also been conducted to study the combustion characteristics of pulverized coal in bench top burners.

These programs form the in-house technical portion of the Sandia Combustion Research Facility. The Facility is a $\$ 10 M$ construction program sponsored by DOE and will be made available to visiting scientists to use the unique capabilities housed there. Offices for resident and visiting staff, an auditorium, a branch library and a specially-designed laboratory building are included in the Facility. Construction is mid-way with final occupancy to occur in late 1980 . 


\section{KINETICS OF SOME REACTIONS OF HCN AT HIGH TEMPERATURES}

\section{R. K. Hanson, C. T. Bowman and A. Szekely Department of Mechanical Engineering Stanford University Stanford, California 94305}

The objective of this research pruyrain is to obtain high-tcmpcratura kinetic data for reactions of HCN. Tliese data are relevant to tho dovolop= ment of proper chemical models for pollutant formation in flames. Reactions of particular interest include the thermal decomposition of $\mathrm{HCN}$ and the reactions of $\mathrm{HCN}$ with $\mathrm{H}, \mathrm{O}$ and NO.

In this study, a shock tube is used to shock-heat various gas mixtures containing $\mathrm{HCN}$ and spectroscopic diagnostics are employed to monitor timehistories of important species during reaction. At the present time, studies in shock-heatéd HCN- $\mathrm{K} r$ mixtures are being cónducted to detenlulut lale coefficients for the reactions

$$
\stackrel{k_{1}}{\mathrm{HCN}}+\mathrm{M} \rightarrow \mathrm{H}+\mathrm{CN}+\mathrm{M}
$$

and

$$
\stackrel{\mathrm{k}_{2}}{\mathrm{H}+\mathrm{HCN}} \rightarrow \mathrm{H}_{2}+\mathrm{CN}
$$

Preliminary measurements of $k_{1}$ in the temperature range $3200-3900 \mathrm{~K}$ are in satisfactory agreement with an extrapolation of the lower temperature data of Roth and Just. Detailed kinetic modeling of the overall decomposition process has shown that for a narrow range of temperatures, $k_{2}$-values can be obtained from the $\mathrm{HCN}$ and $\mathrm{CN}$ concentration profilc data. 


\title{
OBTAINING POSITIVE EVIDENCE FOR THE IMPORTANCE OF VARIOUS PROCESSES IN SOOT FORMATION IN FLAMES
}

\author{
Richard G. Gann, W. Gary Mallard, Kermit C. Smyth \\ Center for Fire Research \\ National Bureau of Standards \\ Washington, D.C. 20234
}

The objective of this study is to develop a fundamental understanding at the molecular level of soot formation processes in combustion, especially the dependences on fuel and additive chemistry. This entails elucidation of specific processes within and about the combustion zone: hydrocarbon cracking and nucleation and particle growth. We are investigating the importance of ionic and free radical processes, the involvement of aromatic and acetylenic intermediates and the contribution of inorganic components.

In recent years, considerable evidence has been obtained in favor of a mechanism which involves nucieation by growth of positive ions. Using laser-induced-enhancement of metal ion concentrations, we are evaluating the prevalence of this process. Our approach clearly separates this effect from that of the neutral metal species.

A second current study involves fluorescent signals observed in a variety of flame configurations (premixed, co-flow diffusion, and counterflow diffusion) for a variety of gaseous and solid fuels. r.learly epccics common Lu such diverse combustion conditions must be considered of importance. Using excitation spectra, we have begun to characterize the responsible species. Further work will identify the role in the sooting process. 
EXPERIMENTAL STUDY OF COMBUSTION IN A TURBULENT BOUNDARY LAYER

$$
\begin{gathered}
\text { F. Robben, R.K. Cheng, R.G. Bill, Jr.*, L. Talbot* } \\
\text { Lawrence Berkeley Laboratory }
\end{gathered}
$$

Combustion in most practical systems takes place in the presence of strong fluid mechanical turbulence. Turbulence has a profound effect on the overall combustion rate and the chemical kinetics; specifically, it is strongly coupled to the completeness of combustion and the generation of pollutants. Our effort is intended to characterize, experimentaliy, the cumbustion process in a welldefined turbulent flow geometry. The results will give qualitative insight into approximations suitable for numerical modelling, and will provide detailed experimental measurements for validation of numerical modelling algorithms.

Initial results have been obtained on induced turbulence in the boundary layer of a $2.5 \mathrm{~cm}$ square channel. One wall of this channel consisted of thin Kanthal heating strips, which created turbulence-like fluctuations due to the resulting uneven surface, and which could be electrically hed led up to $1300 \mathrm{~K}$. Time and space resolved measurements of velocity (laser Doppler anemometry) and density (Rayleigh scattering) have been made using a computerized data acquisition system. From these measurements means, rms fluctuations, probability density functions, and power spectral density functions have been obtained by digital processing.

The experimental conditions covered equivalence ratios from 0 lo 0.3 , wa 11 temperatures between 1100 and $1300 \mathrm{~K}$ and free stream velocities from 14 to $22 \mathrm{~m} / \mathrm{sec}$. A typical Reynolds number based on the free stream velocity was $3 \times 10^{5}$. Three modes of combustion were indicated: 1) surface reaction, 2) surface reaction combined with gas phase redclion in the boundary layer, 3) a flame-like structure situated at the edge of the boundary layer. Velocity fluctuations of about $4 \%$ in the non-heated boundary layer were reduced to $2 \%$ by wall heating. Density fluctuations of 8 to $10 \%$ were.observed in the heated boundary layer both with and without combustion. The maximum density gradient region of the flame-like structure was found to fluctuate at a fairly regular rate of 0.5 to $1.25 \mathrm{Khz}$ depending on various conditions.

*Also Department of Mechanical Engineering, University of California, Berkeley 
D. R. Hardesty

Sandia Laboratories

Turbulence has a dramatic effect on combustion in all practical devices. At present, however, it is virtually impossible to predict this effect. The data base for developing models of turbulent combustion is inadequate. Strictly Eulerian models of turbulent flow fields ignore the existence of large scale coherences in the $f$ low which can have a first order influence on burning rates, flame stability and pollutant production. This state of affairs provides the motivation for the experimental and theoretical studies of reacting and non-reacting turbulent flows which we have undertaken. The principal investigators in this research are G. D. Rambach, R. W. Dibble, R. E. Hollenbach and W. T. Ashurst.

A Turbulent Diffusion Flame Facility (TDFF) has been constructed to permit experimental study of the interaction of fluid mechanics and chemical kinetics in turbulent flames of practical size. The facility permits detailed mapping of axisymmetric turbulent diffusion flames using nonperturbing optical techniques. Velocity and turbulence intensity measurements are obtained by two-color laser Doppler velocimetry (LDV), while temperature, density and major species number densities are measured using $\mathrm{cw}$ and pulsed spontaneous Raman spectroscopy and Rayleigh scattering.

The immediate objectives are to measure single point probability density functions (pdfs), mean values, and fluctuations of velocity, temperature and major species number densities. The LDV and cw Raman data permit calculation of single point autocorrelation functions, which in turn yield local time and length scale information. U1timately nearly simultaneous application of LDV and the pulsed Raman system will permit measurement of single point joint pdfs and cross correlations of velocity, temperature and species number densities.

Initial measurements of radial velocity profiles at 6 axial locations in a turbulent hydrogen/air flame will be discussed. The data directly yield velocity pdfs and turbulent intensities and will be processed to obtain autocorrelation functions (hence, local time and length scales). We have also explored the feasibility of making time resolved temperature and density, as well as, local autocorrelation function measurements in turbulent premixed and diffusion flames using cw Rayleigh scattering. Results from that study will be reported.

We are also conducting theoretical studies of two dimensional, planar and initially axisymetric shear flows. The method of vortex dynamics has successfully reproduced the unsteady asymmetric flow that occurs in channels with step changes in area and in twodimensional shear layers. Results from these numerical calculations based on a quasistedaly approxtmation of the curbulent flow field will be summarized. 
COMBUSTION OF NITROGEN AND SULFUR BEARING FUELS

K. Schofield and M. Steinberg

Quantum Institute, University of California, Santa Barbara, CA 93106

Our program concerns characterizing and developing quantitative laser fluorescence techniques as a monitor for numerous species in flames. Using a series of well defined $\mathrm{H}_{2} / \mathrm{O}_{2} / \mathrm{N}_{2}$ and $\mathrm{C}_{2} \mathrm{H}_{2} / \mathrm{O}_{2} / \mathrm{N}_{2}$ flames of varied compositions and temperatures we have previously validated measurements of $\mathrm{OH}, \mathrm{SO}_{2}, \mathrm{SO}_{2} \mathrm{SH}, \mathrm{s}_{2}$ and CS concentrations based on a technique which corrects to a very close approximation for variations in the flame to flame and flame posttiun to position quenrh environment. We are writing a series of three papers concerning these detailed characterizations and will include a discussion of the exalt meshanism by whirh sulfur species catalytically reduce the radical concentration levels.

These data have unravelled the major chemistry of sulfur in fuel rich $\mathrm{H}_{2} / \mathrm{O}_{2} / \mathrm{N}_{2}$ flames. Corresponding data have been obtained with $\mathrm{C}_{2} \mathrm{H}_{2} / \mathrm{O}_{2} / \mathrm{N}_{2}$ flames. but waits detailed analysis.

We are concentrating our attention now on monitoring the nitrogen bearing species $\mathrm{NO}, \mathrm{NO}_{2}, \mathrm{CN}, \mathrm{NH}$, and $\mathrm{NH}_{2}$ and have analyzed the optimal spectral regions for laser excitation and detection to avoid interferences particularly for environments that may be polluted with sulfur or other species.

Experiments initially will involve obtaining both laser excitation and fluorescence spectra to identify the best combination of wavelengths for these five species. The relative concentration flame profiles will be derived as a function of downstream time in a number of flames to examine interrelationships, kinetic coupling and state of equilibration.

Absolute calibration presently requires the laentification of a regtur of: theimal equilibration, generally a location far duwislicam in ono of the highest temperature flames. Alternate techniques are being considered and may or may

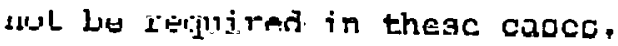

It is our final plan to examine the coupling between these species of the No $x$ cycle to those of So $_{x}$ using flames containing both sulfur and fuel nitrogen to identify whether this involves a direct interaction or indirectly results from the known effects each cycle has on the radical concentrations.

An additional laser system is being acquired by the Quantum Institute (Quanta Ray Yag pumped dye laser) and will be available to us further extending our excitation capability to range from the near infrared to the vacuum ultraviolet 1 imit. 


\section{LASER SCHLIEREN/SHOCK TUBE STUDIES \\ OF HYDROCARBON PYROLYSIS}

J. H. Kiefer

University of Illinois at Chicago Circle

This research involves use of the laser schlieren technique to measure pyrolysis rates of various fuel hydrocarbons. The technique is indicated for this purpose because of its extremely high time resölution (@ $0.05 \mu \mathrm{sec}$ ) and direct response to endothermic rate, which allows determination of "initial", rates with minimal interference from secondary processes.

We have built a new and refined apparatus which allows considerable improvement in measurement accuracy. Preliminary results of experiments on rare gases and rare gas-hydrocarbon mixtures will be shown to the extent available.

A very detailed and rigorous study of the physical optics of the laser-beam shock wave interaction has been completed. The purpose here was complete identification of all features of the schlieren signal, in particular the vexing and critical problem of time-origin location. 
THE DIRECT DETERMINATION OF ATOM AND RADICAL CONCENTRATIONS IN THERMAL REACTIONS OF HYDROCARBONS AND OTHER GASES

\author{
G. B. Skinner \\ Wright State University \\ Dayton, $\mathrm{OH} 45435$
}

The aim of this research is to learn more about the detailed kinetics of combustion processes by measurements of $\mathrm{H}, \mathrm{O}, \mathrm{OH}, \mathrm{CH}_{3}$ and similar. species, which are generally considered to be important in propagating the reactions, but which have seldom been observed directly. So far we have concentrated on measuring $H$ (and 0 ) atom concentrations by resonance absorption spectroscopy in shock-heated gases.

We previously. reported on line shape and calibration measurements for $H$ and $D$ atoms, and measurements of these atoms in $H_{2}-O_{2}-A r, D_{2}-O_{2}-A r$, $\mathrm{CD}_{4}-\mathrm{Ar}$ and $\mathrm{CD}_{4}-\mathrm{O}_{2}$-Ar mixtures.

During the past year we have continued to measure $H$ and $D$ atom concentrations in a series of mixtures of $\mathrm{C}_{2} \mathrm{H}_{6}, \mathrm{C}_{2} \mathrm{D}_{6}, \mathrm{C}_{3} \mathrm{H}_{8}$, and $\mathrm{C}_{3} \mathrm{D}_{8}$, with and without the presence of oxygen. Kinetic analysis of the data has generally confirmed mechanistic inferences made indirectly by other methods, and led to new measurements of rate constants for some elementary reactions.

We are now replacing the optical filter system used to measure $H$ and $D$ atoms by a monochromator, which we will first use to measure 0 atom concentrations in several of the above mixtures. 


\title{
HIGH TEMPERATURE FAST FLOW REACTOR STUDIES
}

OF FUEL NITROGEN REACTIONS

\author{
W. J. McLean* \\ Cornell University \\ Ithaca, New York
}

\begin{abstract}
The reactions governing the fate of various nitrogenous compounds in combustion systems continue to be of interest as ways are sought to utilize alternative fuel resources while strictly limiting $\mathrm{NO}_{\mathbf{x}}$ emissions. A high temperature fast flow reactor has been built to enable us to examine the details of several reactions involving simple nitrogenous compounds under carefully controlled conditions. The reactor system follows the earlier successful design of Fontijn. The construction of the reactor system is complete as are all flow and temperature calibrations. Analytical methods for product analysis by gas chromatography have been established.

Initially the flow reactor is being used to study the reaction between $\mathrm{NH}_{3}$ and NO. This system was chosen because of its importance in practical efforts to reduce $\mathrm{NO}_{x}$ emissions, and because data from simple, non-combusting environments are required to support modeling efforts underway elsewhere. In this presentation our initial results for the reaction of dilute mixtures of $\mathrm{NH}_{3}$ and NO in helium in the temperature range $900 \mathrm{~K}$ to $1300 \mathrm{~K}$ are reported.

`Current Address: Sandia Laboratories, Livermore, California
\end{abstract}




\section{PULSE RADIOLYSIS STUDIES ON REACTIONS RELATED TO COMBUSTION AND AIR POLLUTION}

S. Gordon, M. C. Sauer, C. Jonah, and R. Lii Chemistry Division Argonne National Laboratory Argonne, IL 60439

Ising the method of pulse radiolysis, we have produced species such as $\mathrm{OH}, \mathrm{HO}_{2}$ and $\mathrm{O}^{3}(\mathrm{P})$. We have studied the reaction between $\mathrm{OH}$ and $\mathrm{HO}_{2}$, an important termination step in combustion and atmospheric chemistry, at $308^{\circ} \mathrm{K}$ and find the rate constant for this reaction to be $\mathrm{k}=(1.00 \pm 0.13) \times 10^{-10} \mathrm{~cm}^{3} \mathrm{molec}^{-1} \mathrm{sec}^{-1}$. Values reported by others range from $3 \times 10^{-11} \mathrm{~cm}^{3}$ molec $^{-1} \mathrm{~s}^{-1}$. at low pressures to a value in excess of $10^{-10} \mathrm{~cm}^{3} \cdot$ molec $^{-1} \cdot \mathrm{sec}^{-1}$ reported at higher pressure and in the presence of water vapor: Complexing of $\mathrm{HO}_{2}$ by water vapor appears to have no discernible effect on the reaction. We have also determined the temperature. dependence $\left(290-400^{\circ} \mathrm{K}\right)$ of the gas phase disproportionation of $\mathrm{HO}_{2}$ in the presence of $\mathrm{H}_{2} \mathrm{O}$ and $\mathrm{NH}_{3}$. Analysis of the results yields values of $\Delta \mathrm{H}_{298}^{\mathrm{O}}=-10.5 \mathrm{kcal} / \mathrm{mole}$ and $\Delta \mathrm{G}_{298}^{\mathrm{U}}=-2.7 \mathrm{kcal} / \mathrm{mole}$ for the $\mathrm{HO}_{2}-\mathrm{NH}_{3}$ complex. In the cases of $\mathrm{HO}_{2}-\mathrm{H}_{2} \mathrm{O}$ ermplex, tho $\Delta \mathrm{II}_{298}^{\circ}$ value is in the range of -9 to $-10 \mathrm{k}, \mathrm{g} 1, \mathrm{mn} 1 \mathrm{e}$ and $\Delta \mathrm{G}_{290}^{\circ}$ is in the range of -0.1 to $-1.1 \mathrm{k}$ cal/mole. We have alsu determined a negative activation energy for the reaction of $\mathrm{HO}_{2}$ with $\mathrm{HO}_{2}$ in the gas phase and the results have been explained in terms of an unstable $\mathrm{HO}_{2}$ dimer intermediate. In addition, the rate constant for the reaction of $\mathrm{O}^{3}(\mathrm{P})$ with $\mathrm{HO}_{2}$ at $298^{\circ} \mathrm{K}$ has been determined, the value obtained being $(4.0 \pm 0.8) \times 10^{-11} \mathrm{~cm}^{3} \operatorname{molec}^{-1} \mathrm{~s}^{-1}$. 
We have started a program to extend our measurements of rate constants of elementary reactions of interest in combustion to higher temperatures using our pulse radiolysis technique. This involves at first adopting resonance absorption techniques to our pulse radiolysis methods. Reactions of the $\mathrm{OH}$ radical have been measured at $298^{\circ} \mathrm{K}$ using this technique. Rate constants of $2.57 \times 10^{-13} \mathrm{~cm}^{3} \mathrm{molec}^{-1} \mathrm{~s}^{-1}$ for $\mathrm{CO}$ and $4.5 \times 10^{-13} \mathrm{~cm}^{3} \mathrm{molec}^{-1} \mathrm{~s}^{-1}$ for $\mathrm{NH}_{3}$ have been determined in the process of checking out the technique. In addition, equipment is being assembled to produce specific state excitation of radicals using a narrow band tunable dye laser in an effort to understand non-Arrhenius behaviors of these radicals.

$I_{R}$. Lii, R. A. Gorse, Jr., M. C. Sauer, Jr. and S. Gordon; J. Phys. Chem. 83, 1804 (1979). 


\section{CHEMKIN: A GENERALIZED CHEMICAL KINETICS CODE PACKAGE}

R. J. Kee

Sandia Laboratories

Livermore, CA 94550

\section{ABSTRACT}

A uscr oriented cone package has beell written to define chemical kinetirs equations in a transportable, computationally efficient, and problem independent format. Usc of the CHEMKIN packaye frees the uscr from the tedium nf writing the : FORTRAN code necessary to describe his chemical mechanism. Besides eliminating the programming time needed to describe or modify a reaction mechanisin, the symbolic input to CHEMKIN significantly reduces the chance of error.

Using the CHEMKIN package begins by providing to it a symbolic description of an elementary chemical reaction mechanism. Thermodynamic properties for the chemical species involved are either extracted from the NASA fits to JANNAF data or may be input by the user. Over 100 subroutines are provided in the package to compute and return information on the thermodynamic state. of the gas, derivatives of chemical production rates, or sensitivity coefficients. These variabies are then combined and used by the user in whatever form is appropriate for his particular problem.

Since the CHEMKIN package isn't designed to solve problems directly, the user must write some FDRTRAN code of his own to describe his problem. However, given a set of equations that he wants to solve, a user will find that the CHEMKIN package provides the subroutines that define those terms in his equations which relate to chemical production and thermodynamics. His programming therefore, is minimal, since he only needs to call CHEMKIN subroutines and combine the results to define his problem. By making the package highly modular and problem independent, it is directly usable on a very large class of problems without modification. 


\section{THE DISSOCIATIVE RECOMBINATION OF $\mathrm{H}_{3} \mathrm{O}^{+}$}

J. B. A. Mitchel1, P. M. Mul, and J. Wm. McGowan

Department of Chemistry Brookhaven National Laboratory, Upton, New York 11973 and Department of Physics, University of Western Ontario, London, Ontario, Canada N6A $3 \mathrm{~K} 7$

Studies of ionization phenomena in flames are important to our complete understanding of the chemical kinetics of these systems and to the practical problem of nucleation and soot formation. $\mathrm{H}_{3} \mathrm{O}^{+}$is known to be an important flame ion, being formed via the reactions:

$$
\begin{aligned}
\mathrm{CH}+\mathrm{O} & \longrightarrow \mathrm{CHO}^{+}+\mathrm{e} \\
\mathrm{CHO}^{+}+\mathrm{H}_{2} \mathrm{O} & \longrightarrow \mathrm{H}_{3} \mathrm{O}^{+}+\mathrm{CO}
\end{aligned}
$$

Since electrons are the dominant negatively charged component in flames, decay of $\mathrm{H}_{3} \mathrm{O}^{+}$is assumed to proceed via dissociative recombination

$$
\begin{aligned}
& \mathrm{H}_{3} \mathrm{O}^{+}+\mathrm{e} \longrightarrow \mathrm{H}_{3} \mathrm{O}^{* *} \longrightarrow \mathrm{OH}+\mathrm{H}+\mathrm{H} \\
& \longrightarrow \mathrm{H}_{2} \mathrm{O}+\mathrm{H}
\end{aligned}
$$

Absolute cross sections for dissociative recombination have been measured experimentally using a merged beam apparatus in which a beam of fast electrons is superimposed on a high energy beam of molecular ions from a Van de Graaff accelerator. By suitable matching of the velocities of the two beams, center of mass interaction energies can be varied over a wide energy range $(<0.01 \mathrm{eV}$ to $>1.0 \mathrm{eV})$ corresponding to a temperature range of $\left(<100^{\circ} \mathrm{K}\right.$ to $>11000^{\circ} \mathrm{K}$ ). Results ${ }^{1}$ for $\mathrm{H}_{3} 0^{+}$have revealed that below $1000^{\circ} \mathrm{K}$, the rate coefficient exhibits a $\mathrm{Te}^{-0.5}$ temperature variation deviating to a $\mathrm{Te}^{-1.5}$ variation above $1000^{\circ} \mathrm{K}$. Its value at $2000^{\circ} \mathrm{K}$ was found to be $1.6 \pm 0.25 \times 10^{-7}$ $\mathrm{cm}^{3} \mathrm{sec}^{-1}$. These findings are in good agreement with tho trappcd ion otudico of Heppner et al. 2 but are in total disagreement with the results of Hayhurst and Telford ${ }^{3}$ who found a positive temperature variation in the range $2000-2500^{\circ} \mathrm{K}$ using mass spectrometric sampling from flames. It is proposed that this difference is due to errors in the analysis of the flame sampling procedure.

1. J. Wm. McGowan, P. M. Mul, V. S. D'Angelo, J. B. A. Mitche11, P. Defrance, and H. K. Froelich, Phys. Rev. Lett. $\underline{42}, 373$ (1979).

2. R. A. Heppner, F. L. Wa11s, W. T. Armstrong, and G. H. Dunn, Phys. Rev. A 13,1000 (1976).

3. A. N. Hayhurst and N. R. Telford, Proc. Roy. Soc. A $\underline{322}, 1999$ (1974).

Work supported by U.S. Department of Energy and Canadian Natural Sciences and Engineering Kesearch Council.

NO ORAL PRESENTATION WAS MADE. 


\section{KINETICISTS - INFORMAL SESSION: SUMMARY}

D. Gutman, Chairman

An informal meeting was held at this time to initiate a discussion on the possibility of identifying and defining important basic problems in the field of combustion kinetics. It was stressed that any problem(s) selected should be amenable to "solucton" In a reasonabic period of time if a concerted effort were made hy the group of kineticists present. Methane oxidation was proposed as an example of such a prublem sincc it can be considered a suluet of more complex combustion mechanisms, and is often a model system for testing practical combustion devices. It is also the combustion system in which details of $\mathrm{NO}_{x}$ and $\mathrm{SO}_{\mathrm{X}}$ production wechaniome can be most tasily atudied. Much is already known about the mechanism.

The discussion began with many questions being raised, e.g. who would benefit from more knowledge about methane oxidation? Is the system too simple to be of interest to anyone? Would study of a more complex system like propane oxidation be of more value for understanding the combustion of real fuels? Does such a system have enough unsolved problems to interest more than just a few people? Should soot formation and $\mathrm{NO}_{\chi}$ and $\mathrm{SO}_{\chi}$ chemistry be separated topics for special study? There were no opinions expressed that methane oxidation would not be a "solvable" problem. 'There were comments that some topics (such as soot formation), although extremely important, are too complex to yield new insights from a relatively short intensive effort by combustion scientists.

Attempts to answer these questions raised many more and it became apparent that, due to the wide spectrum of interests represented by those present, it would not be possible to reach a concensus on the subject in the short time available. Further discussion would be required to determine which chemical problem to single out as being not only significant but also of sufficient interest to the group as a whole to obtain a sizeable commitment of people's time and resources lowards providing various parts of the desired solution.

There was a clear interest in continuing the dialog because of the obvious value of the objective. It was suggesled that communication be continued through a newslerter which could aleo serve to inform a broader community in combustion research about the latest developments in the fleld. There was extensive discussion on the form and content that such a newsletter should have as well as on the means for publishing the newsletter. Relating to the latter question, a recommendation was made to initiate production of the "Combustion Kinetics Newsletter"as an addendum to the Combustion Research Facility newsletter, which is published by Sandia Laboratories. It was suggested that a smaller group be appointed to prepare suggestions and a Newsletter Scoping Committee was formed at the closing session of the contractor's meeting. This committee is comprised of the following members: 


\section{David Gutman \\ Wing Tsang \\ William J. McLean \\ Richard. Gann \\ 0 . William Adams}

Suggestions on the format and content of the proposed Newsletter and ideas related to the basic combustion problem are being solicited and may be sent to Dr. Adams or any of the members of the Newsletter Scoping Committee. 
COMBUSTION GAS MEASUREMENTS

USING TUNABLE LASER ABSORPTION SPECTROSCOPY

R. K. Hanson

Stanford University

Objectives of this research are: (1) the development of tunable laser absorption techniques for measuring species concentrations and temperature; and (2) the measurement of fundamental spectroscopic parameters (line strengths and collision halfwidths) of critical species under combustion conditions. Work thus far has emphasized tunable infrared diode lasers, lut additfonul work with a tunable ring dye laser for absorption spectroscopy at uv and visible wavelengths has been initiated recently.

Experiments involve passing a monochromatic laser beam through gases in a flat flame burner, a shock tube or a static absorption cell and subsequently tuning the laser wavelength across isolated vibration-rotation or electronic absorption lines, thereby obtaining records of fully-resolved absorption line profiles. When the species concentration and temperature are known, the absorption data yield determinations of line strengths and collision halfwidths. In experiments where these fundamental parameters arc already knnwn, then the same measurcment techniques can be used to Infer the absorbing species concentration and temperature.

The narrnw linewidth of single-frequency diode lasers and dye lasers enables orders-of-magnitude improvemenl in spectral resolution nver conventional absorption spectroscopy. As a result, it is now possible to directly determine absorption lineshape parameters under combustion conditions, while previlouely blese parnmeters were inferred indirectly, usually with substantial uncertainties. In addition, by employing fast scanning techniques, tunable laser absorption also offers prospects for time-resolved, nonperturbing measurements in combustion gases.

Work during the past year has included diode laser measurements of $\mathrm{CO}$ and NO and dye laser measurements of $\mathrm{Na}$. 
MEASUREMENT OF RADICAL SPECIES CONCENTRATION IN FLAMES BY FLUORESCENCE AND ABSORPTION USING A TUNABLE DYE LASER

\author{
N. M. Laurendeau, D. W. Sweeney, and R. P. Lucht \\ School of Mechanical Engineering \\ Purdue University \\ West Lafayette, IN 47907
}

Saturated fluorescence is being investigated as a potential diagnostic method for determining the concentrations of selected diatomic radicals $(\mathrm{OH}, \mathrm{CN}, \mathrm{NH}, \mathrm{CH})$ using atmospheric and subatmosperhic flat flame burners. A Molectron DLl6 dye laser, pumped by a Molectron MY32 pulsed.Nd: YAG laser, is used to supply tunable output across the ultraviolet and visible spectrums. The fluorescence spectrum is analyzed to assess the influence of the laser. radiation and various quenching species $\left(\mathrm{H}_{2} \mathrm{O}, \mathrm{Ar}, \mathrm{N}_{2}\right)$ on the excited state number density and rotational distribution.

Preliminary experiments have shown that the laser system possesses sufficient power to saturate the $\mathrm{OH}$ radical. It has also been found that the excited state rotational distributions are far from Boltzmann; a steady state rotational distribution is not achieved in one atmosphere flames due to the short pulse length of the Nd: YAG pumped dye laser.

A molecular fluorescence model has been developed for the case where the laser pulse length is comparable to or less than the characteristic rotational relaxation time. Two sets of rotatinnal levels are considered, and it is assumed that the laser is tuned to an isolated rotational transition. For saturation or near saturation conditions, a quasi-equilibrium is established much more quickly between the upper and lower rotational levels which are directly connected by the laser radiation than is established throughout the rest of the rotational levels. By considering fluorescence only from the dircctly excited upper rotational level, data analysis is simplified because a two level model is applicable. It is concluded that short pulse length dye laser excitation offers significant advantages for saturated fluorescence measurements, provided that fluorescence can be observed from an isolated rutational transition and that coherent optical effects can be ignored. 
LINE SHAPE STUDIES IN INTRACAVITY ABSORPTION

\author{
G. O. Brink \\ Department of Physics and Astronomy \\ State University of New York at Buffalo \\ Nmherst, New York 14260
}

The phenomenon of intracavity absorption in a $\mathrm{cw}$ tunable dye laser is being investigated as a potential diagnostic method for the detection of low density atoms, molecules and free radicals in combustion systems. It has already been demonstrated that the method is extremely sensitive, but before it can be applied it is necessary to obtain an understanding of the phenomenon itself. To this end a series of experiments are being conducted to obtain detailed line shape information in a carefully controlled experimental system.

Results obtained to date using Intracavity atomic beams of sndiull and barium indicate that the line shape is complex exhibiting both absorption and entancement features. The only previous theory is based on a rate equation model which predicts that the line shape should be the same as that of the absorber. This is not observed to be the case, and it now appears lhal lle late equation modal, at least in itss present. form, can not account for the data.

A new model has been developed, based on an analogy between a cw multimode dye laser and a super-reqenerative oscillator, which does. predict a line shape in qualitative agreement with that observed under certain circumstances. It is possible that extension of the model will permit it to account for all features of the line shape. 


\section{REAL TIME OPTICAL DIAGNOSTICS}

\section{R. Goulard}

The George Washington University

Combustion applications are surveyed and the experimental parameters needed for the choice of the most reliable models is being identified quantitatively. These parameters and their range of usefulness determine the diagnostics technique which should best apply.

A special effort is being made to match diagnostics progress with the current high interest in turbulent eddy diffusion and decay. This application emphasizes the need for the collection of concentration and temperature maps in three dimensions, hopefully within the time span characteristic of turbulent mixing situation.

One laboratory effort in progress consists of the optical tomography of a turbulent diluted methane jet. Preliminary results in the steady state (carried out at NBS) will be discussed: The next step concerns real time measurements at $10 \mathrm{KHz}$ : it is currently being designed and will be discussed briefly.

The advent of subnanosecond laser pulses and very short time-gating techniques is opening several possibilities. One is to make use of the time differences between signal response and noise response to laser pulses (e.g. Raman vs. fluorescence), as well as to reduce soot emission by shorter time gates. Also, the space resolution corresponding to a picosecond is less than a millimeter. Therefore, it seems possible to transpose such time gating techniques as Raman lidar and Differential absorption lidar to the laboratory with available sources and sensors. This new remote sensing scheme (Picosecondlidar) would permit more rapid scanning of flames than conventional point scattering techniques. This part of the investigation is carried out in association with $\mathrm{Dr}$. K. G. P. Sulzmann (LaJolla Institute and UCSD). 


\title{
ADVANCED DIAGNOSTIC METHODS FOR COMBUSTION RESEARCH*
}

\author{
P. L. Mattern \\ Sandia Laboratories
}

The purpose of this DBES-funded research program is to develop diagnostic methods for the analysis of combustion systems. Recent accomplishments include:

A novel method for eliminating non-resonant background in CARS measurements was demonstrated in a mellane/air flame. Signalto-tuicise nf $C \Omega$ was improved by a factor of $\sim 200$ over "normal." CAkS. $N_{2}$ and $C O$ cemperatures ullained by comparison with. theory were consistent with thermocouple measurements. Co Qbranch region was shown to have major contributions from $\mathrm{N}_{2}$ and $\mathrm{H}_{2}$.

U1tra-high.resolution ( $\sim 25 \mathrm{MHz}$ ) coherent Raman spectra of $\mathrm{H}_{2}$, $\mathrm{D}_{2}, \mathrm{CH}_{4}$ were obtained as a function of pressure. First measurements of hydrogen line-width vs. pressure from Doppler-limit through Dicke-narrowed to pressure-broadened region were published. First fully-resolved data on $\nu_{1}$-branch in $\mathrm{CH}_{4}$ were fit to theory with high accuracy.

Ultra-high resolution ( $130 \mathrm{MHz}$ ) inverse Raman measurements were carried out on $\mathrm{N}_{2}, \mathrm{CO}$, and $\mathrm{H}_{2}$ in a methane/a1r flame. The first fully-resolved spectra of $\mathrm{N}_{2}{ }^{2}$ In a llame sliwwed a line width dependence on rotational quantum number. Experiments at room temperature showed a different line-width dependence on $\mathrm{J}$. Results appear to be described by a simple phenomenological model of rotational relaxation.

Near shot-noise-limited single-pulse measurements of methane gas density were obtained at room temperature using stimulated Raman scattering.

Incandescent contributions to spontaneous Raman scattering signals in a sooting flame were reduced by over two orders of magnitude by using $351 \mathrm{~nm}$ excitation: $\mathrm{N}_{2}$ temperature-related data were oblalned.

Spatially-resolved ESR spectra were obtained from $\mathrm{O}_{2}$ in a cell. ESR has been used to detect and otudy atomic $H$ in 1 atmosphere $\mathrm{H}_{2}$ /air and $\mathrm{CH}_{4}$ /air diffusion flames.

Calculations show that large changes in combustion chemistry can be obtained by pumping forbidden transitions in pre-existing atomic oxygen in a hydrngen/air mixture at elevated temperatures.

*Research supported by the U. S. Department of Energy 


\section{SPECTROSCOPY OF SOME COMBUSTION REIATED SPECIES}

\section{J.C. Hindman}

Argonne National Laboratory

Argonne, Ill. 60439

The goal of this research is to study the chemical interactions leading. to electron production or loss of electron density in an MHD plasma. As part of this program we have undertaken the development of laser diagnostic techniques for monitoring gas phase species of interest.

A detailed study of the coherant anti-Stokes Raman Spectroscopy. (CARS) of the $\mathrm{NO}_{2}$ molecule has been undertaken. This molecule was chosen for study since it is an example of a number of gas phase molecules and radicals where resonance enhancement might be expected to increase the sensitivity for detection." Coherant anti-Stokes resonance fluorescence emission (CAFE) has been abserved for resonance excitation of $\mathrm{NO}_{2}$ using an optical pumping geometry similar to CARS spectroscopy.

We have also looked at the CARS spectroscopy of a number of OH containing molecules. our interest here has been to determine whether this method could be used for dectection of the $\mathrm{OH}$ radical. 


\section{COMBUSTION RESEARCH CONTRACTORS' MEETING}

Brookhaven National Laboratory

October 9-11, 1979

\section{PARTICIPÁNTS}

ADAMS, $0 . W$.

Division of Chemical Sciences

Office of Basic Energy Sciences

U.S. Department of Energy

Washington, DC 20545

BARKER, J . R.

Chemical Kinetics Group

SRI Internationa1

Menlo Park, CA 94025

BOWMAN, C . T .

Mechanical Engineering Department

Stanford University

Stanford; CA 94305

BREZINSKY; $K$.

Department of Mechanical Engineering

Princeton University

Princeton, NJ 08540

BRINK, G. 0 .

Department of Physics and Astronomy

State University of New York at Buffalo

Amherst, NY 14260

BUSS, R. J.

Materials and Molecular Research Division

Lawrence Berkeley Laboratory

University of California

Rerkeley, rA 94720

CAMPILLO, A. J.

Department of Energy and Environment

Broukhaven National Laboratory

Upton, NY 11973

CURTIS, $\mathrm{P}$.

Department of Chemistry

Brookhaven National Laboratory

Upton, NY 11973

DUNNING, T.

Chemistry Division

Argonne National Laboratory

Argonne, IL 60439
ENGELKING, P.

Department of Chemistry

University of Oregon

Eugene, OR y7403

FARRAR, J. M.

Department of Chemistry

The University of Rochester

Kochester, NY 14621

FELDER, W.

AeroChem Research Laboratories, Inc. P. O. Box 12

Princeton, NJ 08540

FRIEDMAN, I.

Department of Chemistry

Brookhaven National Laboratory.

Upton, NY 11973

GAFFNEY, J. S.

Department. of Energy and Environment

Brookhaven Nat1onal Laboratory

Upton, NY 11973

GANN, $R$.

National Bureau of Standards

Washington, DC 20234

GURTUN, S :

Argonne National Laboratory

9700 S. Cass Avenue

Argonne, IL 60439

GUULAKV, R.

School of Engineering and Applied Science

The George Washington University

Washington, DC 20052

GROVER, J. R.

Department of Chemistry

Brookhaven National Laboratory

Upton, NY 11973 
GUILLORY, W. A.

Department of Chemistry

University of Utah

Salt Lake City, UT 84112

GUSINOW, M. A.

Combustion Sciences Department 8350

Sandia Laboratories

Livermore, CA 94550

GURINSKY, D. H .

Department of Energy and Environment Brookhaven National Laboratory

Upton, NY 11973

GUTMAN, D.

Department of Chemistry

Illinois Institute of Technology

Technology Center

Chicago, IL 60616

HANSON, R. K.

Mechanical Engineering Department

Stanford University

Stanford, CA 94305

HARDESTY, D. R.

Combustion Research Division 8353

Sandia Laboratories

Livermore, CA 94550

HINDMAN, J. C.

Argonne National Laboratory

9700 S. Cass Avenue

Argonne, IL 60439

HOWELLS, M. R.

Department of Physirs

Brookhaven National Laboratory

Upton, NY 11973

HUDIS, J .

Department of Chemistry

Brookhaven National Laboratory

Upton, NY 11973

$\mathrm{KEE}$, R. J.

Applied Mathematics Division

Sandia Laboratories

Livermore, CA 94550

KERN, R. D.

Department of Chemistry

University of New Orleans

New Orleans, LA 70122
KIEFER, J.

Department of Energy Engineering

University of Illinois at Chicago Circle Box 4348

Chicago, IL 60680

KLEINMAN, L. I.

Department of Energy and Environment Brookhaven National Laboratory

Upton, NY 11973

KLEMM, R. B.

Department. of Energy and Environment Brookhaven National Laboratory

Upton, NY 11973

KRISHNA, C. R.

Department of Energy and Environment Brookhaven Nationa1 Laboratory

Upton, NY 11973

KROGER, P. M.

Department of Chemistry

Brookhaven National Laboratory

Upton, NY 11973

LAW, C. K.

Department of Mechanical Engineering and Astronautical Sciences

Northwestern University

Evanston, IL 60201

LEE, J. H .

Department of Energy and Environment Brookhaven National Laboratory

Upton, NY 11973

LE'S'IER, W. A.

National Resource for Computation in Chemistry

Lawrence Berkeley Laboratory

Berkeley, CA 94720

LIVINGSTON, $\mathrm{R}$.

Chemistry Department

Oak Ridge National Laboratory

nak Ridge, TN 37830

MARLOW, W. H.

Department of Energy and Environment

Brookhaven National Laboratory

Upton, NY 11973 
MATTERN, P: L.

Applied Physics Division 8342

Sandia Laboratories

Livermore, CA 94550

McLEAN, W. J .

Combustion Sciences Department 8350

Sandia Laboratories

Livermore, CA 94550

MELIU3, C .

Combustion Sciences Department 8350

Saridia Laboratories

Livermore, CA 94550

WETE, D, J .

Department of Energy and Environment Brookhaven National Laboratory

Upton, NY 11973

MITCHELL, J. B . A.

Department of Chemistiry

Brookhaven National Laboratory

Upton, NY 11973

MUCKERMAN, J. T.

Department of Chemistry

Brookhaven National Laboratory

Upton, NY 11973

NEWMAN, L .

Department of Energy and Environment Brookhaven National Laboratory

Upton, NY 11973

NEWTON, M. D.

Department of Cliemistry

Brookhaven National Laboratory

Upton, NY 11973

NG, C. Y.

Mol.ecular Sciences Program

Ames Laboratory

Iowa State University

Ames, IA 50011

O'HARE, T. E.

Department of Energy and Environment Brookhaven National Laboratory

Upton, NY 11973

PRESES, J.

Department of Chemistry

Brookhaven Nationa1 Laboratory

Upton, NY 11973
QUICK, C. R.

Department of Chemistry

Brookhaven National Laboratory

Upton, NY 11973

RABITZ, H.

Department of Chemistry

Princeton University

Princeton, NJ 08540

RAVISHANKARA, A. R.

Energy and Environmental

Anulye1s Divisinn

Applied Sciences Laboratury

Engineering Experimental Station

Georgia Institute of Technology

Atlanta, GA 3033ź

REI'I', R.

Courant Tnstitute of Mathematical

Sciences

Now York In i.versity

251 Mercer Street

New York, NY 10012

ROBBEN, F.

Energy and Environment Division

Lawrence Berkeley Laboratory

Berkeley, CA 94720

RUEDENBER( $;$, K.

Ames Laboratory

Iowa State University

Ames, IA 50011

SCHLYER, D. J .

Department of Chemistry

Brookhaven National Laboratory

Upton, NY 11.97 .3

SCHOFIELD, $\mathrm{K}$.

Quantum Institute

University of Calffornla

Santa Barbara, .CA 93106

SKINNER, G. B.

Department of Chemistry

Wright State University

Dayton, OH 45435

STEINBERG, M.

Department of Energy and Environment

Brookhaven National Laboratory

Upton, . NY 11973 
SUTHERLAND, J. H.

Department of Energy and Environment Brookhaven National Laboratory

Upton, NY 11973

SWEENEY, D. W.

School of Mechanical Engineering

Purdue University

West Lafayette, IN 47907

TANZAWA, $T$.

Department of Energy and Environment

Brookhaven National Laboratory

Upton, NY 11973

TRUHLAR, D.

Department of Chemistry

University of Minnesota

Minneapolis, MN 55455

TSANG, $W$.

Kinetics Information Center

Building 222

National Bureau of Standards

Washington, DC 20234

TULLY, F, P.

Energy and Environmental Analysis Division Applied Sciences Laboratory

Engineering Experimental Station

Georgia Institute of Technology

Atlanta, GA 30332

WAGNER, A. F.

Chemistry DIvision

Argonne National Laboratory

9700 S. Cass Avenue

Argonne, IL 60439

WESTON, R. E.

Department of Chemistry

Brookhaven National Laboratury

Upton, NY 11973

WHITLOCK, P. A.

Courant Institute of Mathematical. Sciences

New York University

251 Mercer Street

New York, NY 10012
WINSCHE, W. E. Directors office

Brookhaven National Laboratory Upton, NY 11973

WOLK, G. L.

Department of Chemistry

Brookhaven Nationa1 Laboratory Upton, NY 11973 